Article

\title{
Electric Vehicle Charging Load Allocation at Residential Locations Utilizing the Energy Savings Gained by Optimal Network Reconductoring
}

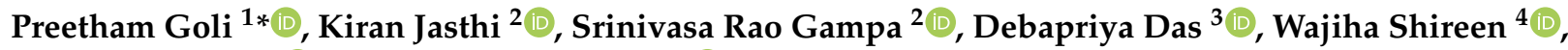 \\ Pierluigi Siano ${ }^{5,6}$ (1) and Josep M. Guerrero ${ }^{7}$
}

check for

updates

Citation: Goli, P.; Jasthi, K.; Gampa, S.R.; Das, D.; Shireen, W.; Siano, P.; Guerrero, J.M. Electric Vehicle Charging Load Allocation at Residential Locations Utilizing the Energy Savings Gained by Optimal Network Reconductoring. Smart Cities 2022, 5, 177-205.

https://doi.org/10.3390/ smartcities5010012

Academic Editor: Andrea Bonfiglio

Received: 26 January 2022

Accepted: 11 February 2022

Published: 16 February 2022

Publisher's Note: MDPI stays neutral with regard to jurisdictional claims in published maps and institutional affiliations.

Copyright: (C) 2022 by the authors. Licensee MDPI, Basel, Switzerland. This article is an open access article distributed under the terms and conditions of the Creative Commons Attribution (CC BY) license (https:// creativecommons.org/licenses/by/ $4.0 /)$.
1 Department of Computer Science and Electrical Engineering, University of Missouri Kansas City, Kansas City, MO 64110, USA

2 Department of Electrical \& Electronics Engineering, Gudlavalleru Engineering College, Gudlavalleru, Krishna District, Vijayawada 521356, India; jasthikiran88@gmail.com (K.J.); gsr_gsrinu@yahoo.co.in (S.R.G.)

3 Department of Electrical Engineering, Indian Institute of Technology, Kharagpur 721302, India; ddas@ee.iitkgp.ac.in

4 Department of Engineering Technology, University of Houston, Houston, TX 77004, USA; wshireen@uh.edu

5 Department of Management \& Innovation Systems, University of Salerno, Via Giovanni Paolo II, 132, 84084 Fisciano, SA, Italy; psiano@unisa.it

6 Department of Electrical and Electronic Engineering Science, University of Johannesburg, Johannesburg 2006, South Africa

7 Center for Research on Microgrids (CROM), Department of Energy Technology, Aalborg University, 9220 Aalborg, Denmark; joz@energy.aau.dk

* Correspondence: golip@umkc.edu

\begin{abstract}
In this study, a two-stage methodology based on the energy savings gained by optimal network reconductoring was developed for the sizing and allocation of electric vehicle (EV) charging load at the residential locations in urban distribution systems. During the first stage, the Flower Pollination Algorithm (FPA) was applied to minimize the annual energy losses of the radial distribution system through optimum network reconductoring. A multi-objective function was formulated to minimize investment, peak loss, and annual energy loss costs at different load factors. The results obtained with the flower pollination algorithm were compared with the particle swarm optimization algorithm. In the second stage, a simple heuristic procedure was developed for the sizing and allocation of EV charging load at every node of the distribution system utilizing part of the annual energy savings obtained by optimal network reconductoring. The number of electric cars, electric bikes, and electric scooters that can be charged at every node was computed while maintaining the voltage and branch current constraints. The simulation results were demonstrated on 123 bus and 51 bus radial distribution networks to validate the effectiveness of the proposed methodology.
\end{abstract}

Keywords: flower pollination algorithm; radial distribution system; particle swarm optimization; reconductoring; electric vehicles

\section{Introduction}

Electric vehicles (EVs) are becoming an integral part of the urban distribution systems to compensate for the global energy crisis due to the depletion of fossil fuels and to minimize the pollution levels. Uncoordinated EV charging at the parking lots in residential areas overloads the feeders and distribution transformers, thereby degrading the voltage profile of the distribution system. To overcome these ramifications, various strategies have been developed for optimum EV load demand management at residential locations.

Reconductoring involves the selection of optimal conductor sizes in the branches of the radial distribution network to minimize the cost and energy losses. The efficiency 
gained by network reconductoring allows the utility grid to supply EV load while maintaining satisfactory performance. Several methods are discussed in the literature on the reconductoring of radial distribution networks. Wang et al. [1] proposed a heuristic-based index considering non-uniform load distribution for network reconductoring. Mandal and Pahwa [2] proposed a method of selecting a conductor set based on load ranges by considering several engineering and financial factors. Ranjan et al. [3] described an evolutionary programming method to obtain the optimal conductors by considering the annualized cost of losses and the capital cost. Satyanarayana et al. [4] proposed a simple heuristic method for improving the maximum current carrying capacity of the distribution systems. Kaur and Sharma [5] proposed an algorithm for optimal conductor selection by considering the cost of energy and power, increase in load demand, and load factor. Rao et al. [6] proposed a harmony search algorithm-based method for optimum conductor selection. Franco et al. [7] presented a model for reconductoring of radial distribution systems using a mixed-integer linear programming approach. Abdul [8] proposed a step-by-step approach for optimal conductor selection for distribution systems. Samal et al. [9] proposed a differential evolution-based planning methodology for optimal capacitor allocation and conductor size selection for unbalanced radial distribution systems. Abdelaziz et al. [10] proposed a crow search algorithm, and Sherif et al. [11] presented Salp Swarm Optimization (SSO) algorithm for optimal conductor selection. Gampa et al. [12] proposed a FPA Pareto optimality-based approach for network reconductoring of distribution systems integrated with solar photovoltaic units. Burgio et al. [13] proposed a heuristic approach for determining the capacity of residential photovoltaic battery systems in distribution networks to provide flexible services to the grid. In this work, Flower Pollination Algorithm (FPA) was applied for network reconductoring since it has better convergence properties and guarantees a globally optimum solution compared to popular swarm-based and population-based optimization algorithms such as PSO and genetic algorithm (GA).

Accurate modeling of EV load is necessary to study the impact of EV charging on the distribution network. Determining the impact of EV proliferation on the distribution network is a thoroughly studied problem by the research community. Garcia and Vlachogiannis [14] developed PQ models for EV charging load demand for load flow studies as a function of charging time-based on queuing theory. Shireen et al. [15] studied the impact of EV chargers on the distribution network and proposed various solutions to mitigate the impact. Van den Berg et al. [16] proposed a methodology to determine the charging demand of future EV fleets in an office area and determine its flexibility potential. Brinkel et al. [17] proposed an approach for mitigating the grid congestion in LV grids by using shared EVs. Iria et al. [18] and Nick et al. [19,20] proposed the application of energy storage devices, network reconfiguration, and voltage regulators to reduce the congestion in a distribution system with EVs. Marra et al. [21] studied the characteristics of the demand profile considering different EV battery charging options. Guo et al. [22] analyzed the impact of large-scale penetration of EVs on the grids. Zhang et al. [23] proposed EV charging load models based on customers' demographics, traveling probabilities, charging preference, and energy consumption rates. Hecht et al. [24] presented the analysis on the requirement of different types of chargers based on the time of parking of the electric vehicles at the charging stations.

The influx of a large number of EVs from various manufacturers requires the utilities to determine the optimal locations to install charging station infrastructure. A comprehensive body of literature is available on the placement of EV charging stations. Sachan and Kishor [25] have derived voltage sensitivity indices from the inverse Jacobian matrix from the Newton-Raphson load flow-based approach to identify optimum EV charging locations. Gampa et al. [26] proposed grasshopper optimization algorithm based on a two-stage fuzzy multi-objective approach for optimum allocation of EVs, Distributed Generators (DGs), and Shunt Capacitors (SCs). Luo et al. [27] developed a comprehensive model for optimal allocation of DGs and EV charging stations with the target of achieving optimum annualized costs. Li et al. [28] applied a chance-constrained programming method for 
charging and discharging power scheduling of an EV charging station. Bayram et al. [29] proposed a probabilistic planning methodology for peak load management in a distribution network with PEV charging lots through the allocation of energy storage systems. Fan et al. [30] proposed a multi-objective mixed-integer nonlinear program-based framework for distribution system planning considering stochastic models of renewable energy sources and electric vehicles. Mehrjerdi and Hemmati [31] proposed a stochastic model for electric vehicle charging stations integrated with energy storage systems and wind energy. Rahmani et al. [32] studied planning and operational problems of EV parking lots considering a traffic and drivers behavioral model. Parastvand et al. [33] proposed a graph-based method for the placement and sizing of EV charging stations considering traffic for limiting the vehicles' waiting time at the charging station. Surest et al. [34] developed a hybrid optimizer based on ant colony optimization to allocate EV charging stations in a microgrid. Richardson et al. [35] analyzed the impact of local versus centralized controlled charging strategies of EV batteries on low-voltage distribution networks. Fachrizal and Munkhammar [36] proposed distributed and centralized smart charging schemes for EVs at residential buildings for minimizing the net load variability utilizing photovoltaic power generation.

Mitigation of the adverse impacts of EVs on the distribution network requires effective load management practices. EV load management techniques and scheduling methods have been well addressed in the literature. Coffman et al. [37] studied the role of residential solar PV supply systems to meet electric vehicle charging demand and reduce greenhouse gas emissions. Khalkhali [38] proposed a stochastic mixed-integer linear programming approach to effectively utilize EVs in a parking lot at residential locations for regulation service. Ayyadi et al. [39] proposed a linear programming-based approach for minimizing $\mathrm{EV}$ charging cost considering the uncertainties in EVs' arrival and departure. Gong and Ionel [40] proposed utilizing energy storage systems charged with PVs at smart homes to compensate EV load demand at evening peak hours. Ahmadi et al. [41] proposed JAYA algorithm-based charging and discharging scheduling of EVs for minimizing the daily load variance. Limmer and Rodemann [42] proposed a framework for scheduling the EV charging process based on dynamic price offers for reducing peak load and maximizing charging station operating profit. Haes et al. [43] proposed a novel mix complementary programming method for generation mix determination considering demand response, energy storage systems, and electric vehicles. Advancements in Lithium-ion battery technology have been reported in [44-46]. Hou et al. [47] developed a battery efficiency-based scrapping criterion for improving the battery lifetime for effectively managing peak shaving and demand response. Dixon and Bell [48] presented the impact of EVs on distribution systems considering battery chargers' capacity and demographic data of the drivers. Das et al. [49] presented a comprehensive review of the current status of EVs and concluded that further technologically advanced charging infrastructure is required to ensure the maximum benefits from EVs with DGs.

Based on the literature review discussed so far, it can be mentioned that most of the research pertaining to EV grid integration focused on the optimal siting and sizing of EV charging stations and effective EV load management techniques. The proliferation of EVs requires significant upgrades to the distribution system infrastructure, such as overhead conductors and distribution transformers. Since the majority of customers charge their EVs at home during the nighttime, it is essential to determine the maximum EV charging load that can be accommodated at the residential locations. However, not much work in the literature focuses on the distribution system upgrades at optimal cost to accommodate the future influx of EVs. This work aimed to fill the gap in the literature through optimal network reconductoring and allocation of the EV charging load at residential locations by utilizing the energy savings obtained from network upgradation.

Several researchers proposed optimal charging rates for EV batteries based on their state of charge, availability at the residential parking locations, and network conditions using local and centralized charging control techniques. The main disadvantage of these 
techniques is that they require effective communication infrastructure and different charging rates shortening the battery life span [35]. Recently, many authors have proposed techniques based on rooftop photovoltaic (PV) power for EV load management. However, the power from the solar PV units is not available during the early morning and night time and is uncertain during the rainy and winter seasons. The mismatch between PV power generation and EVs charging schedules during various seasons requires expensive battery energy storage systems. Moreover, the uncertainties in renewable energy sources may not support the charging requirements at home during all the seasons. Since customers are not at home during midday when maximum PV generation occurs, they can only charge the EVs during the weekends [27,37]. For the residential customers who return home in the evening, it is advantageous to charge their EVs from the power outlets, and maintaining an additional backup of EV batteries is not economical. Furthermore, wind energy is directly connected to the transmission grid, and the chances of connecting to the urban distribution systems are meager $[50,51]$. Smart grid technologies such as demand response techniques are primarily favorable to the customers who can operate their load according to the prices offered by the utilities [52]. Though voltage regulators can be utilized to improve the voltage profile, they cannot be employed as permanent solutions. Since EV charging is advantageous during off-peak hours and battery energy storage systems (BESS) are expensive for residential customers, the utilities are required to supply the required EV charging load. In the case where the renewable energy sources along with the smart grid technologies are not sufficient to compensate the significant penetration of EV load, distribution networks must be reinforced using techniques such as network reconductoring to supply power from the substations satisfying network constraints. Optimal network reconductoring not only improves the current-carrying capacity but also minimizes the real power losses and improves the energy savings, especially during peak hours. The energy savings obtained during peak hours can be effectively utilized to accommodate EV charging load during off-peak hours.

In view of the drawbacks associated with EV load management using PVs and energy storage, this article proposes a two-stage design methodology for optimum EV load allocation at each node of the residential distribution systems. In the first stage, optimal reconductoring of the radial distribution network was carried out by using the Flower Pollination Algorithm (FPA). In the second stage, a simple heuristic design methodology was developed to calculate the maximum possible EV load at each node of the distribution system utilizing the energy savings gained by optimal network reconductoring. In this work, it was considered that the additional EV load is supplied from the utility grid to the reconductored distribution system, and the EV charging was considered during evening peak hours and off-peak hours. In addition, the utilization of PV systems for performance improvement of distribution systems during peak hours was analyzed. The contributions of the study can be summarized as:

- Flower Pollination Algorithm (FPA) was applied to reconductor the distribution network while satisfying the voltage and current constraints.

- A heuristic methodology was developed to allocate the EV charging load at every node in a residential distribution network without any violation of the system operational constraints.

- The effectiveness of the proposed algorithms was demonstrated through various case studies performed on 51 bus and 123 bus test systems.

- The methodology proposed in this work will be a valuable tool for power engineers working with distribution utility management to allocate EV charging load efficiently.

\section{Problem Formulation}

Recently, the Flower Pollination Algorithm (FPA) has been successfully applied to solve many power engineering problems since it has a better convergence rate compared to other metaheuristic techniques like GA and PSO, especially when the number of parameters to be optimized are considerably large [53]. The number of branches required for optimum 
reconductoring will increase as the size of the distribution system increases and needs to be analyzed with more conductor types. Moreover, several authors successfully applied FPA to solve power and energy problems [12,54]. Hence, in this work initially, a FPA-based methodology was developed for optimum network reconductoring of radial distribution systems. In the second stage, a simple heuristic design methodology was developed for EV load allocation at residential locations utilizing the energy savings gained by network reconductoring. The network reconductoring was aimed at minimizing annual energy losses at different load factors, conductor cost, and cost of peak load losses.

\subsection{Objective Function}

The objective function for the reconductoring problem in radial distribution systems was formulated by considering the capital cost of the reconductoring, the annual cost of energy losses at different load factors, and the cost of peak load losses. The cost objective function $\left(J_{F}\right)$ can be expressed mathematically by the following equation.

$$
J_{F}=\gamma \sum_{i=1}^{N B} C_{i} L_{i}+K_{e} \sum_{L F=1}^{3} \sum_{j=1}^{N B} I_{j, L F}^{2} R_{j} T_{L F}+K_{P} R P L_{\text {peak }}
$$

where $\gamma$ is the annual interest and depreciation factor, $C_{i}$ is the cost of the conductor in the $i$ th branch, $L_{i}$ is the length of branch $i$ in $\mathrm{km}, K_{e}$ is the cost of energy loss in $R s . / \mathrm{kWh}, I_{j, L F}$ is the current in branch $j$ for the load factor $L F, R_{j}$ is the resistance of the $j$ th branch, $T_{L F}$ is the annual distribution load $\mathrm{h}$ at the load factor $L F, K_{P}$ is the cost for peak loses in $R s . / \mathrm{kW}$, and $R P L_{\text {peak }}$ is the base case peak load.

\subsection{Voltage and Current Constraints}

The following equations describe the constraints considered for the bus voltage and branch current carrying capacity in the proposed approach.

The bus voltage constraint can expressed as follows

$$
V_{\min } \leq\left|V_{b}\right| \leq V_{\max }
$$

where $V_{\min }$ and $V_{\max }$ are the minimum and maximum bus voltage limits and $\left|V_{b}\right|$ is the voltage magnitude at node ${ }^{\prime} b^{\prime}$, respectively. In the proposed approach, $V_{\min }=0.95 \mathrm{pu}$ and $V_{\text {max }}=1.05 \mathrm{pu}$ were chosen for analysis.

The current through any branch should be less than the maximum current carrying capacity of the conductor chosen for that particular branch. This constraint is expressed as follows

$$
I_{j, k} \leq I_{\max , k}
$$

where $I_{j, k}$ is the current in branch $j$ with conductor type $k . I_{\max , k}$ is the maximum current carrying capacity of conductor type $k$.

The rest of the article is organized as follows: Basics of the FPA algorithm and the application of FPA to network reconductoring are discussed in Section 3. Section 4 discusses the energy and economic savings calculations. In Section 5, the EV battery charging load model for load flow analysis is developed, and in Section 6, the mathematical equations required for utilizing energy savings are developed. Section 7 presents the heuristic design procedure for EV load allocation. Finally, the analysis of the results and conclusions are discussed in Sections 8 and 9.

\section{FPA for Network Reconductoring}

The flower pollination algorithm [53] is one of the nature-inspired algorithms. The primary purpose of a flower is to reproduce flower species via pollination processes. So, the flower pollination process involves transferring pollen from one place to another place with the help of pollinators. 
Biotic (cross-pollination) and abiotic (self-pollination) are two primary forms of pollination. In biotic pollination, the pollination process occurs with the help of pollinators such as birds, insects, and animals. These pollinators move over long distances and their behavior can be mimicked with a Levy flight distribution. On the other hand, the abiotic pollination process does not require any pollinators. The abiotic pollination can be expressed with the help of the Levy distribution function as follows

$$
x_{i}^{t+1}=x_{i}^{t}+\gamma_{L} L(\lambda)\left(\text { gbest }-x_{i}^{t}\right)
$$

where $x_{i}^{t}$ is the solution vector of conductor types of branches at generation $t, \gamma_{L}$ is a factor to control the step size, gbest is the present best solution of current iteration/generation, and $L(\lambda)$ is the strength of pollination, which is randomly drawn from a Levy distribution.

$$
L(\lambda) \sim \frac{\lambda \Gamma(\lambda) \sin \left(\frac{\pi \lambda}{2}\right)}{\pi s^{\lambda+1}}
$$

where $\lambda$ is assigned a value of 1.5 for better convergence of the solution; $\Gamma(\lambda)$ is a standard gamma function, and $s$ is greater than zero for large step size. The most advanced technique for getting small step sizes for equivalent Levy distribution numbers generations is the Mantegna algorithm (M), which can be expressed by the following equation.

$$
M(\omega)=\frac{X}{|Y|^{1 / \omega}}, X \sim\left(0, \sigma^{2}\right), Y \sim(0,1)
$$

where $X \sim\left(0, \sigma^{2}\right)$ indicates the random samples drawn from Gaussian normal distribution with zero mean, and $\sigma^{2}$ is the variance. Mathematically, variance $\sigma^{2}$ is calculated as

$$
\sigma^{2}=\left[\frac{\Gamma(1+\omega) \sin \left(\frac{\pi \omega}{2}\right)}{\Gamma\left(\frac{1+\omega}{2}\right) \omega 2^{\frac{(\omega-1)}{2}}}\right]^{1 / \omega}
$$

The reproduction concept of biotic and abiotic flower pollination can be utilized for network reconductoring of distribution systems. The biotic pollination can be written mathematically using the Mantegna algorithm by the following equation

$$
x_{i}^{t+1}=x_{i}^{t}+\gamma_{M} M(\omega)\left(\text { gbest }-x_{i}^{t}\right)
$$

The abiotic or self-pollination can be expressed as

$$
x_{i}^{t+1}=x_{i}^{t}+\varepsilon\left(x_{j}^{t}-x_{k}^{t}\right)
$$

where $x_{j}^{t}$ and $x_{k}^{t}$ are two randomly chosen solutions in generation/iteration $t$, and $\varepsilon$ represents the random number uniformly drawn in the limits [0,1]. $\omega$ is a real number, and its value is considered as 1.5 .

The choice of biotic or abiotic pollination in a particular iteration will be guided by the probability switch " $p$," which was randomly selected. The flowchart for the reconductoring of the radial distribution network using FPA is shown in Figure 1, and the Algorithm 1 is shown below. 


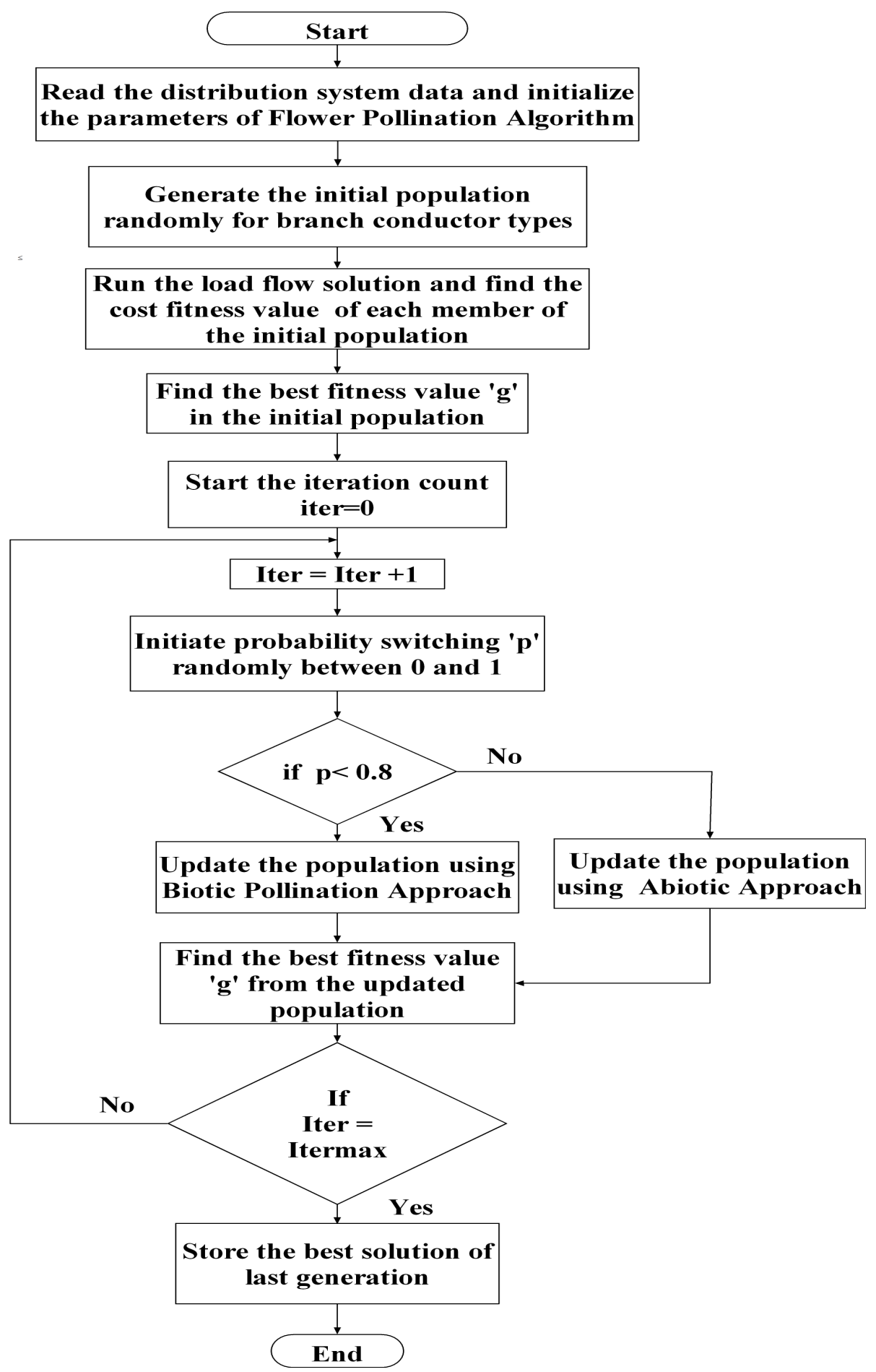

Figure 1. Flowchart for reconductoring using Flower Pollination Algorithm (FPA). 


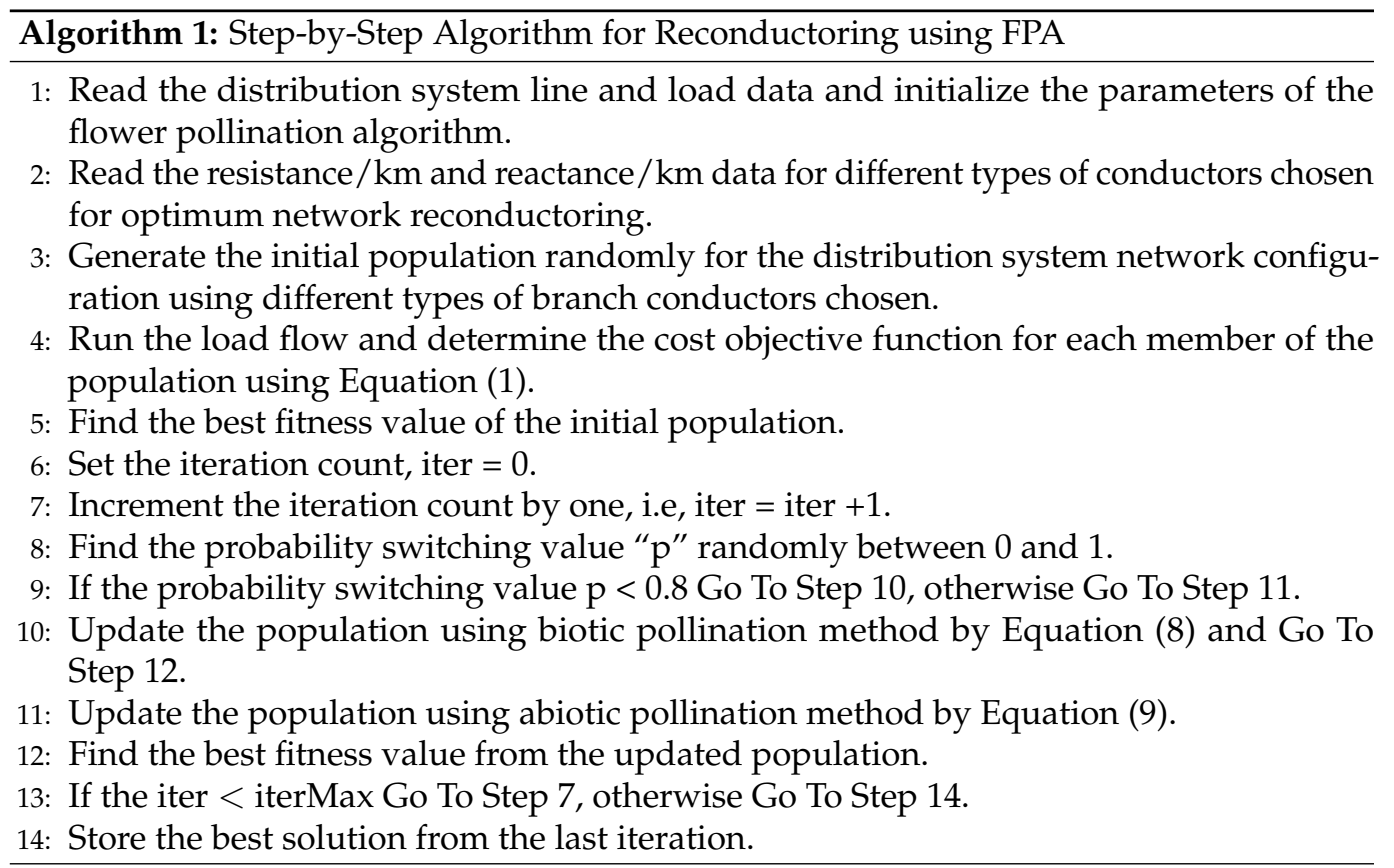

\section{Energy and Economical Savings Due to Network Reconductoring}

The economic savings due to optimal network reconductoring can be obtained by comparing the annual installment paid on the purchase of conductor material cost and annual energy economic savings.

The annual installment payment cost $(A I P)$ on the amount borrowed for the purchase of reconductoring material of the distribution system can be calculated by the following equation.

$$
A I P=\left(\frac{I_{\text {rate }}\left(I_{\text {rate }}+1\right)^{N}}{\left(I_{\text {rate }}+1\right)^{N}-1}\right) \sum_{i=1}^{N B} C_{i} L_{i}
$$

where $I_{\text {rate }}$ is the interest rate, and $N$ is the number of years of installment payment. The annual economic savings can be calculated using the following equations.

$$
\begin{gathered}
A E S C=K_{e} \sum_{L F=1}^{3}\left(R P L_{L F}^{\text {Base }}-R P L_{L F}^{R C}\right) T_{L F} \\
A P L C=K_{p}\left(R P L_{\text {peak }}^{\text {Base }}-R P L_{\text {peak }}^{R C}\right)
\end{gathered}
$$

where AESC is the annual energy savings cost, and APLC is the annual peak loss savings cost. $K_{e}$ is the energy loss cost in Rs. $/ \mathrm{kWh} . R P L_{L F}^{\text {Base }}$ is the base case total power loss at load factor $L F$ before network reconductoring, and $R P L_{L F}^{R C}$ is the total power loss after reconductoring at load factor $L F . R P L_{\text {peak }}^{\text {Base }}$ is the peak power loss due to the base case, and $R P L_{\text {peak }}^{R C}$ is the peak power loss of the distribution system after reconductoring.

The total Annual Economical Savings cost (AECONS) can be obtained by the following equation.

$$
A E C O N S=A E S C+A P L C-A I P
$$

\section{Modeling of EV Charging Load Demand}

Significant penetration of EV charging load causes excessive losses and voltage profile degradation in distribution systems. Hence, the EV charging load models required for load flow analysis can be developed from the power charging characteristics of EV batteries. The charging characteristics of the EV batteries depend on the chemical reactions inside the cells and hence exponential modeling was considered. Lithium-ion batteries are more 
popular and efficient for EV applications, and the following equations can model the exponential characteristic based on constant power and constant voltage charging.

The power charging equation can be expressed as follows when the batteries are charging from an initial state of charge.

$$
P E V(t)=P E V^{\max }\left(1-e^{(-\tau t / T)}\right)+P E V^{0} e^{(-\tau t / T)} \text { for } 0<t<T
$$

where $P E V^{0}$ is the initial charging capacity, and $P E V^{m a x}$ is the maximum charging load of the EV battery. The methodology presented in this article considers the battery charging load in the constant power and constant voltage modes. The standard charging characteristics for the lithium-ion battery are shown in Figure 2. The EV charging demands during constant power and constant voltage charging modes can be expressed by the following equations.

$$
\begin{gathered}
P E V^{C P}(t)=P E V^{\max } \text { for } T_{1} \leq t \leq T_{2} \\
P E V^{C V}(t)=P E V^{\max }\left(\frac{T_{\max }-t}{T_{\max }-T_{2}}\right) \text { for } T_{2}<t \leq T_{\max }
\end{gathered}
$$

where $P E V^{C P}(t)$ and $P E V^{C V}(t)$ represent the EV charging demands during the constant power mode and the constant voltage mode. In Figure 2, the state of charging (SOC) is shown from the start to the fully charged state. The battery rating is expressed generally as battery energy storage capacity $(B E S(t))$ in $\mathrm{kWh}$, and the battery capacity during charging can be represented by the following equations.

$$
B E S(t+1)=B E S(t)+P E V(t) \Delta(t)
$$

The state of the charging of the battery can be expressed by the following equation

$$
\operatorname{SOC}(t)=\frac{B E S(t)}{B E S_{\max }} \times 100
$$

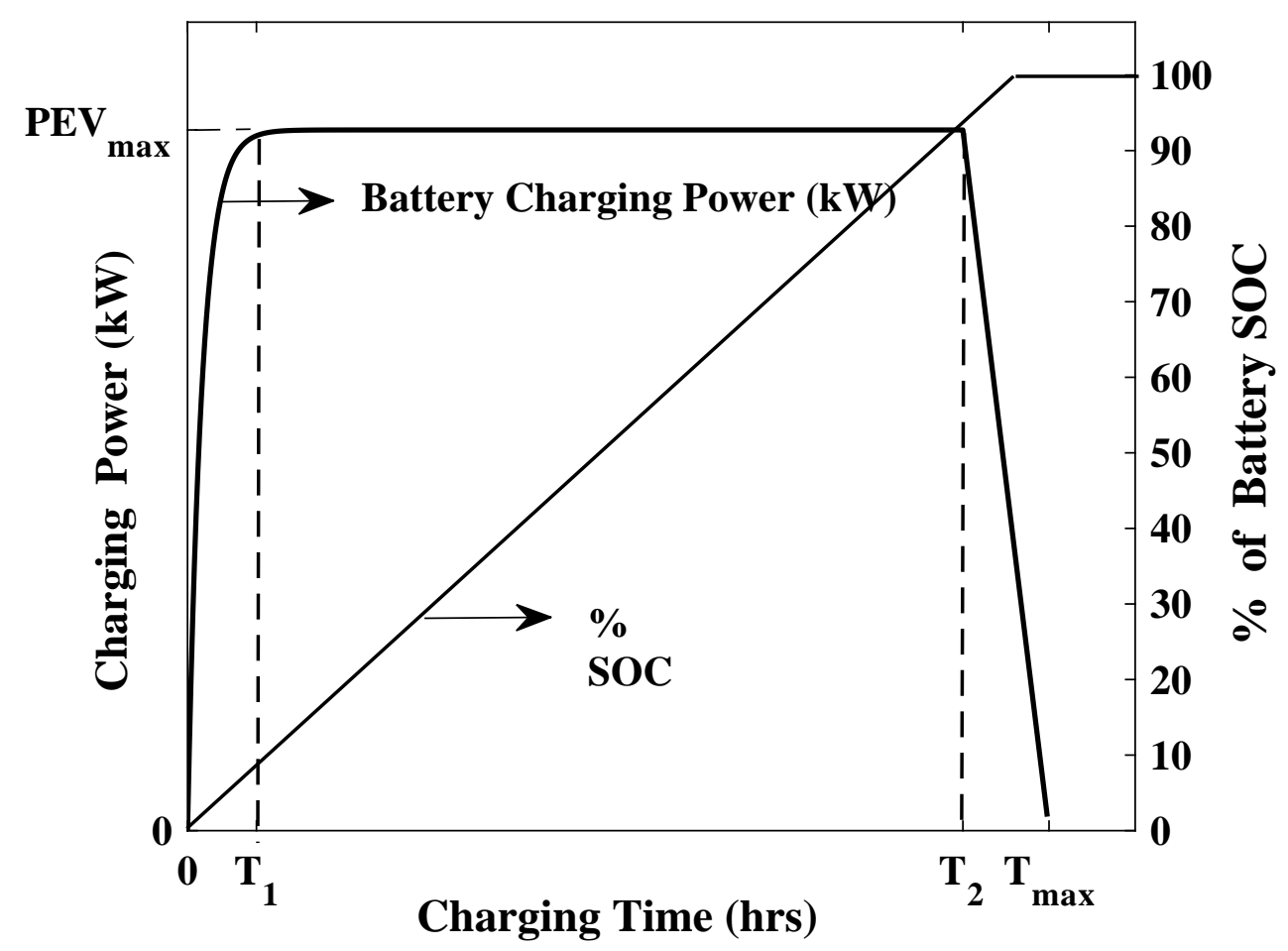

Figure 2. EV battery charging characteristics. 
The EV battery is mainly charged from $20 \%$ to $90 \%$ SOC during the peak charging time [26]. Currently, most of the battery chargers operate at a 0.95 power factor lagging. The batteries are terminated from charging after reaching 100\% SOC to protect the battery from excessive heating, which reduces the number of life cycles of the battery.

\section{Energy Savings Division for EV Load Allocation among Charging Slots}

The EV charging load can be incorporated into the distribution system by utilizing a part of energy savings obtained by network reconductoring while maintaining voltage and current constraints. The present section discusses the energy savings allotment for different charging slots. Initially, the charging slots available are identified, and, later, the energy savings division for EV load among the charging slots is presented.

\subsection{EV Load Charging Slots Division}

The present work considered the distribution system load at three most commonly possible load factors, i.e., at $0.4,0.7$, and 1.0. Each load factor was considered for $8 \mathrm{~h}$ duration per day. The distribution load between 12:00 a.m. and 8:00 a.m. was generally low, and hence a 0.4 load factor was considered during that period. The distribution load generally reached the peak level during the afternoon period, and hence the load factor was considered as 1.0 during the period from 8:00 a.m. to 4:00 p.m. The load was at an average level during the evening hours, and the average load factor of 0.7 was considered during the period between 4:00 p.m. to 12:00 a.m. At each load factor annually $2920 \mathrm{~h}$ were considered.

In most electric vehicles, lithium-ion batteries are used for charging. The time required to charge a medium-range EV battery from $20 \%$ SOC to $90 \%$ SOC is approximately four hours. In general, most of the electric vehicles will be at residential locations for charging between 4:00 p.m. and 12:00 a.m. Since electric vehicles require at least four hours for charging a total of four charging slots can be considered. The distribution load factor and the charging slots division are shown in Figure 3. The charging slots one and two are considered during 12:00 a.m. and 8:00 a.m. at a 0.4 load factor. The charging slots three and four were considered during 4:00 p.m. and 12:00 a.m. at a 0.7 load factor.

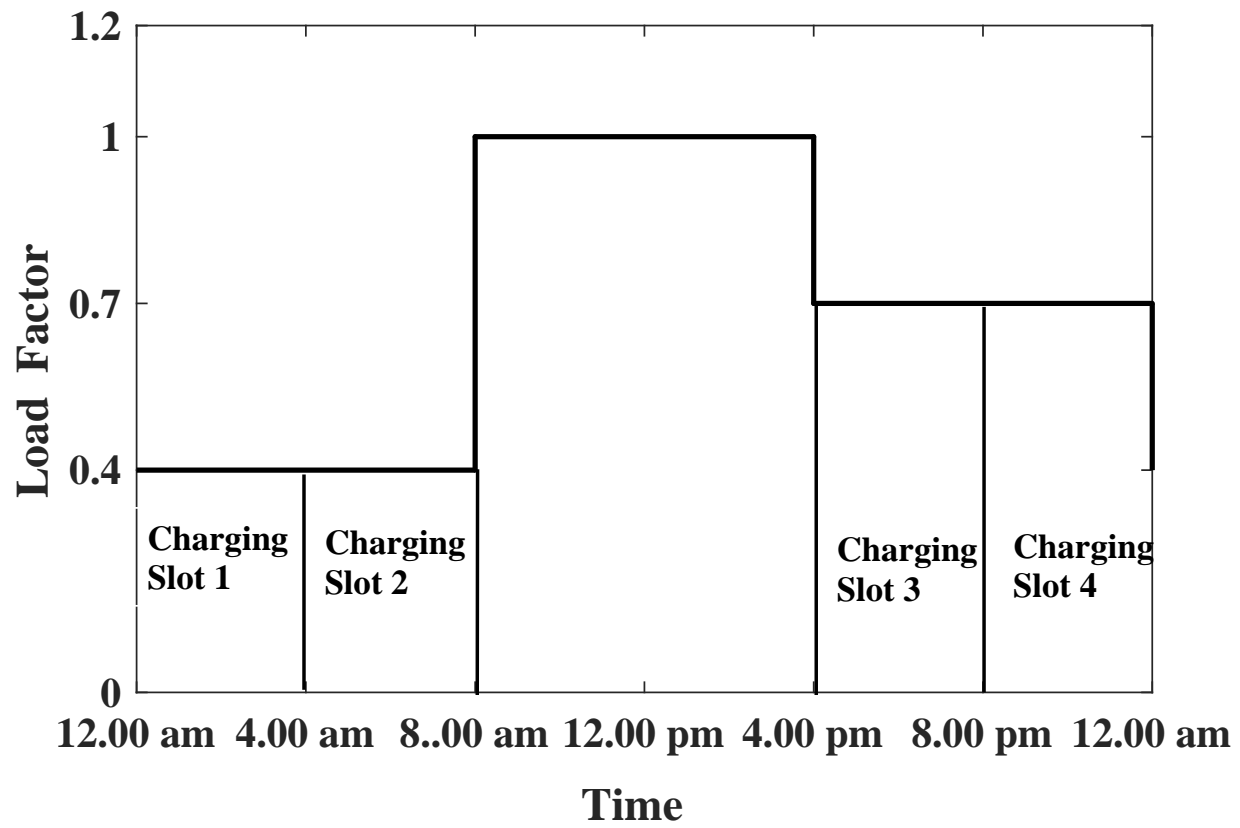

Figure 3. EV battery charging slots. 


\subsection{Energy Savings Division among the Charging Slots}

The maximum EV load that can be accommodated at each charging slot depends on the energy savings available that can be spent during that particular period. In this section initially, the total energy savings that can be spent per day were calculated from the energy savings per day obtained due to optimal network reconductoring, and later they were distributed among the four charging slots. The part of the energy savings $\left(E S_{E V}\right)$ that can be utilized per day for EV load management can be calculated from the following mathematical expression.

$$
E S_{E V}=\frac{\alpha\left(\sum_{L F=1}^{3}\left(R P L_{L F}^{\text {Base }}-R P L_{L F}^{R C}\right) T_{L F}\right)}{365}
$$

where $\alpha$ is the fraction of the energy savings gained from FPA-based network reconductoring, and the value can be taken from 0 to $1 . E S_{E V}$ is the energy savings for $E V$ charging per day; $R P L_{L F}^{\text {Base }}$ is the base case real power loss at the load factor $L F$; and $T_{L F}$ is the annual distribution load hours at the load factor $L F$.

The energy savings division among the four charging slots considered can be represented by the following flow diagram shown in Figure 4.

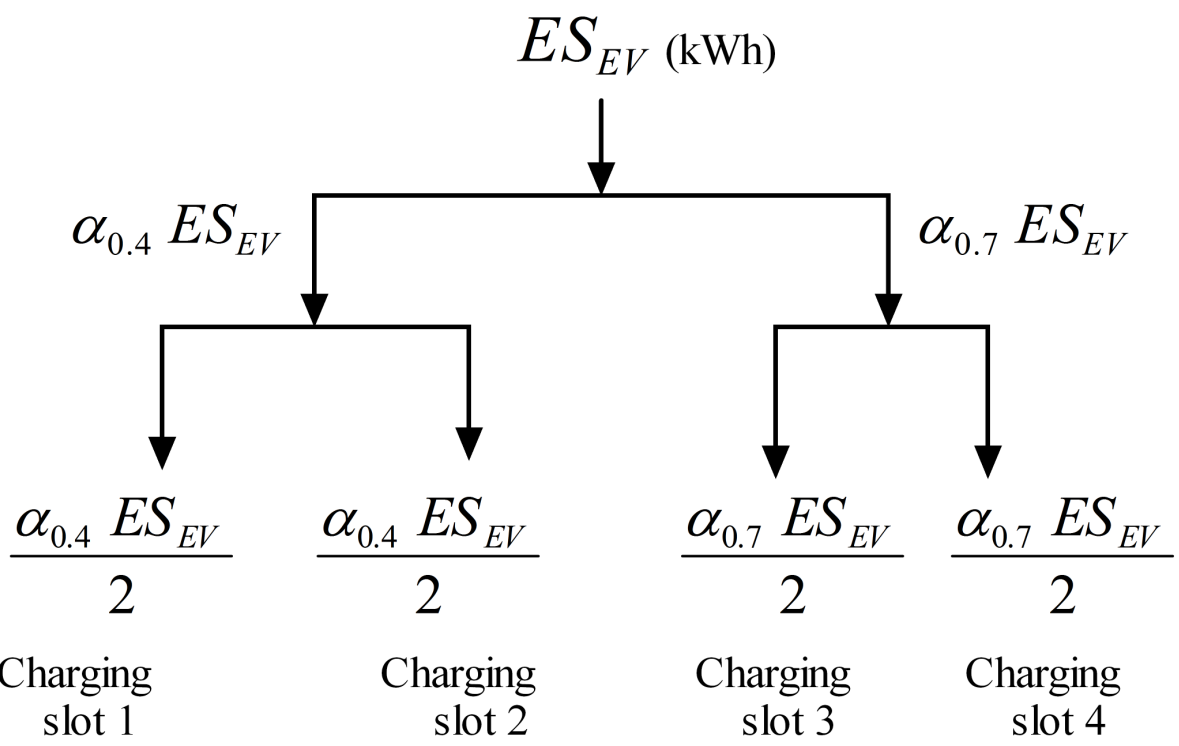

Figure 4. Energy savings division among charging slots.

From Figure 4, it can be observed that the energy savings available are divided between the two load factors, 0.4 and 0.7. In the figure, $\alpha_{0.4}$ and $\alpha_{0.7}$ are the fractions of total energy savings available for EV load, and their sum is equal to unity. It can also be observed from Figure 4 that the available energy savings are equally divided between the two charging slots available at that particular load factor.

The maximum additional permitted power loss of the distribution system with the EV load installation at a particular load factor $R P L_{L F}^{E V_{\max }}$ is determined by the following equation.

$$
R P L_{L F}^{E V m a x}=\frac{\alpha_{L F} E S_{E V}}{N_{E V} T_{E V}}
$$

where $N_{E V}$ is the number of charging slots, and $T_{E V}$ is the time of EV charging. $\alpha_{L F}$ is the fraction of energy savings available at a particular load factor.

\section{Energy Savings Based Heuristic Approach for EV Load Sizing and Allocation}

The EV charging load on the distribution system can be allocated based on real power loss that can be additionally allowed utilizing the energy savings spent during the EV 
charging period. The maximum real power loss during the charging period considering both the distribution system load and the EV charging load can be expressed by the following equation.

$$
R P L_{L F}^{E V R C}=R P L_{L F}^{R C}+R P L_{L F}^{E V \max }
$$

where $R P L_{L F}^{E V R C}$ is the total real power loss with the presence of distribution system load and the permissible EV load at a load factor LF considering the reconductored network.

In the proposed methodology, the EV charging load is considered at all the distribution system nodes. Then, the EV load is added systematically, allowing the real power losses to increase to the permissible limit calculated based on the available energy savings. In this work, a simple heuristic procedure was proposed for determining the maximum EV load at every node of the distribution system. Most modern EV chargers operate at a 0.95 power factor, and real power loss depends on both active and reactive powers. Hence, at every node of the distribution system, a minimum EV load at the 0.95 power factor was considered.

During the first stage of the proposed heuristic method, the minimum active power $P E V_{\min }^{E V}$ and the minimum reactive power $Q E V_{\min }^{E V}$ drawn by the EV load were added simultaneously at every node until the real power loss exceeded the permissible value. In the second stage, the node voltages were arranged in ascending order, and rankings were given starting from the minimum node voltage. Then, the minimum EV load was decreased systematically at the nodes one by one according to their rankings until the real power loss of the distribution system reached the permissible limit. The flow chart representing the proposed heuristic approach is shown in Figure 5, and the Algorithm 2 is shown below.

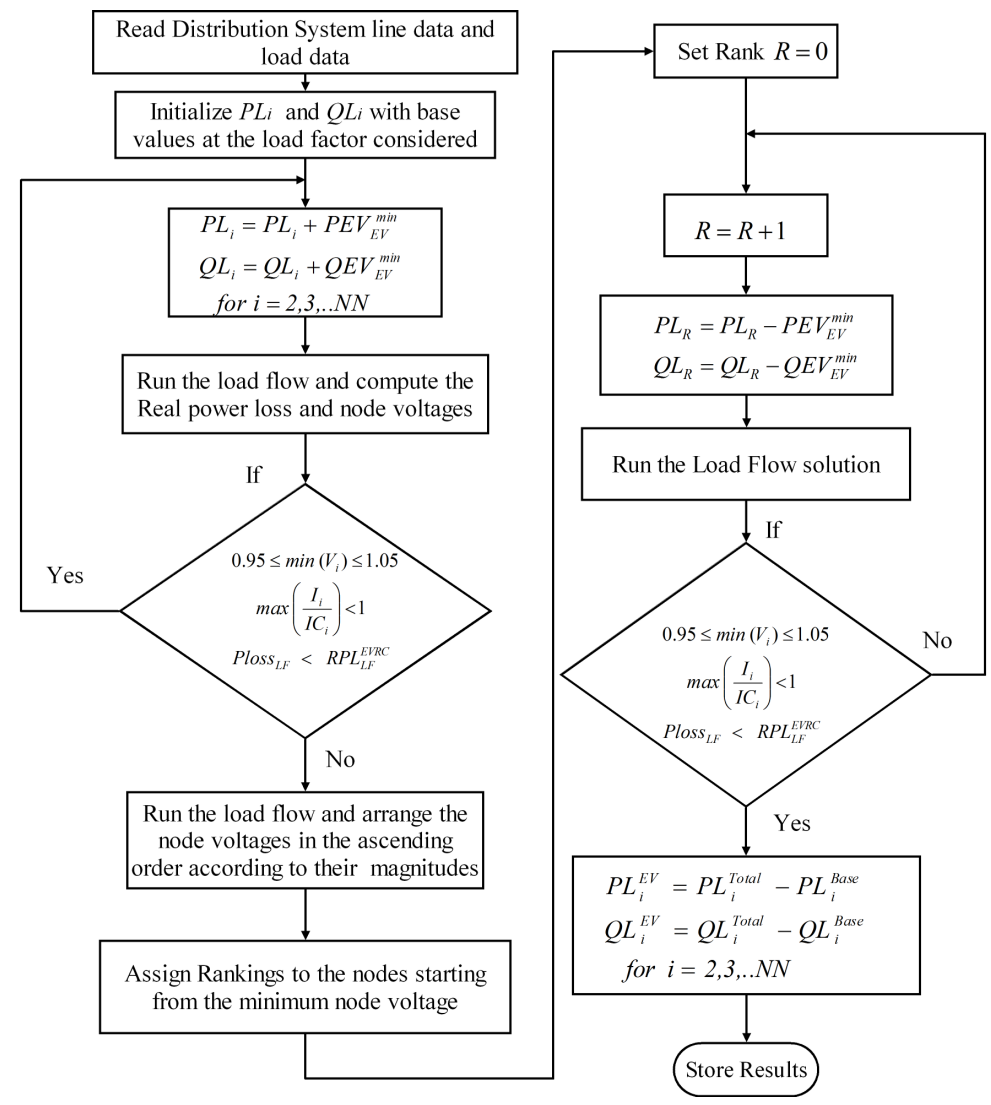

Figure 5. Heuristic approach for EV load allocation. 
Algorithm 2: Step-by-Step Algorithm for the Proposed Heuristic Approach for EV Charging Load Allocation

1: Read the distribution system line data and load data and initialize real and reactive powers at every node with their base values at the load factor considered.

2: The lowest possible EV charging load real power $P E V_{\min }^{E V}$ and reactive power $Q E V_{\text {min }}^{E V}$ are selected.

3: Add the minimum real and reactive powers of EV charging load to real and reactive power loads of the distribution system at every node at the charging slot considered.

4: Run the load flow and obtain the real power loss and node voltages.

5: If the constraints on node voltage limits, branch current limits and maximum permitted loss with EV charging load allocation $R P L_{L F}^{E V R C}$ are satisfied Go To Step 3 otherwise Go To Step 6.

6: Run the load flow and assign the rankings to the nodes starting from minimum node voltage.

7: Set the Rank $\mathrm{R}=0$.

8: Increment the Rank count by one, i.e., $\mathrm{R}=\mathrm{R}+1$.

9: Deduct the minimum real and reactive powers of EV charging load from the real and reactive powers of $R^{\text {th }}$ rank node at the charging slot considered.

10: Run the load flow and obtain the real power loss and node voltages.

11: If the constraints on node voltage limits, branch current limits and maximum permitted real power loss with EV charging load allocation $R P L_{L F}^{E V R C}$ are not satisfied Go To Step 8 otherwise Go To Step 12.

12: Calculate the EV charging load allocated at every node of the distribution system deducting the base loads from the total load.

13: Store the results.

The real and reactive power drawn by the EVs can be obtained at every node by subtracting the base case load from the total load as shown in the following equations.

$$
\begin{gathered}
P L_{i}^{E V}=P L_{i}^{\text {Total }}-P L_{i}^{\text {Base }} \\
Q L_{i}^{E V}=Q L_{i}^{\text {Total }}-Q L_{i}^{\text {Base }}
\end{gathered}
$$

where $P L_{i}^{E V}$ and $Q L_{i}^{E V}$ are the active and reactive power of the EV loads that can be accommodated at each node of the distribution system. $P L_{i}^{\text {Base }}$ and $Q L_{i}^{B a s e}$ are the base case active and reactive power loads of the distribution system, respectively. $P L_{i}^{\text {Total }}$ and $Q L_{i}^{\text {Total }}$ are the active and reactive power loads obtained after the EV load allocation at each node with the proposed methodology.

In residential distribution systems, electric cars, electric bikes, and electric scooters are the most commonly used electric vehicles for transportation. Hence, at every node, the number of EVs that can be accommodated is calculated based on their battery charging capacities.

The priority of the EVs is given based on their battery capacities, which provide the maximum fuel savings. The first priority is the allocation of electric cars; the next priority is electric bikes; and the last choice is electric scooters. The total EV load at a distribution system node must be less than or equal to the EV load limits obtained by the heuristic approach. This can be expressed mathematically by the following equation.

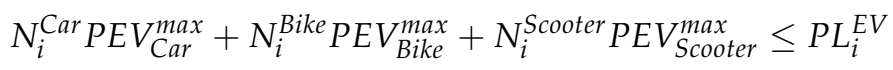

where $P E V_{\text {Car }}^{\max }, P E V_{\text {Bike }}^{\max }$, and $P E V_{\text {Scooter }}^{\max }$ represent the maximum power drawn by the batteries of electric cars, bikes, and scooters during the constant power mode battery charging. 
The maximum number of electric cars that can be accommodated at the $i$ th node is calculated using the following expression

$$
N_{i}^{C a r} \approx \frac{P L_{i}^{E V}}{P E V_{\text {Car }}^{\max }}
$$

where $N_{i}^{C a r}$ is the integer part of the real number obtained by the power ratio shown in the above equation. After allocating the maximum number of electric cars possible, the next choice is electric bikes used for transportation with slightly lower capacity batteries than cars.

The maximum number of electric bikes that can be accommodated is calculated by subtracting the EV car load from the total available EV load.

$$
N_{i}^{\text {Bike }} \approx \frac{P L_{i}^{E V}-N_{i}^{\text {Car }} P E V_{\text {Car }}^{\max }}{P E V_{\text {Bike }}^{\text {max }}}
$$

where $N_{i}^{B i k e}$ is the integer part of the real number obtained by the power ratio shown in the above equation. Similarly, the number of Scooters $N_{i}^{\text {Scooter }}$ is determined from the remaining available EV load after the allocation of electric cars and electric bikes.

$$
N_{i}^{\text {Scooter }} \approx \frac{P L_{i}^{E V}-N_{i}^{\text {Car }} P E V_{\text {Car }}^{\max }-N_{i}^{\text {Bike } P E V_{\text {Bike }}^{\max }}}{P E V_{\text {Scooter }}^{\max }}
$$

\section{Results and Discussions}

In this article, a two-stage methodology is proposed for optimal allocation of maximum possible EV load at residential locations of urban distribution systems utilizing the energy savings gained by optimal network reconductoring.

\section{Optimal Network Reconductoring Using Flower Pollination Algorithm}

In the first stage, the optimal network reconductoring of the radial distribution system was achieved using the flower pollination algorithm. The aggregate of the investment cost of the selected optimal conductors; the cost of annual energy loss of the distribution system at load factors $0.4,0.7$, and 1.0; and the cost of peak load losses was considered as the fitness function for the algorithm. For the three load factors, equal load duration (T), i.e., $2920 \mathrm{~h}$, was considered during a year. The conductor types and their data [55] are shown in Table 1.

Table 1. Conductor Data.

\begin{tabular}{ccccccc}
\hline $\begin{array}{c}\text { Conductor } \\
\text { Type } \\
\text { Number }\end{array}$ & $\begin{array}{c}\text { Conductor } \\
\text { Type }\end{array}$ & $\begin{array}{c}\text { Area } \\
\left(\mathbf{m m}^{\mathbf{2}}\right)\end{array}$ & $\begin{array}{c}\text { Resistance } \\
(\mathbf{\Omega} / \mathbf{k m})\end{array}$ & $\begin{array}{c}\text { Reactance } \\
(\mathbf{\Omega} / \mathbf{k m})\end{array}$ & $\begin{array}{c}\text { Maximum Current } \\
\text { Capacity } \mathbf{( A )})\end{array}$ & $\begin{array}{c}\text { Weight } \\
(\mathbf{K g} / \mathbf{k m})\end{array}$ \\
\hline 1 & Squirrel & 20.71 & 1.374 & 0.355 & 115 & 85 \\
2 & Gopher & 25.91 & 1.09 & 0.349 & 133 & 106 \\
3 & Weasel & 31.21 & 0.9116 & 0.345 & 150 & 128 \\
4 & Ferret & 41.84 & 0.672 & 0.339 & 181 & 171 \\
5 & Rabbit & 52.21 & 0.5449 & 0.335 & 208 & 214 \\
6 & Mink & 62.32 & 0.4565 & 0.333 & 234 & 255 \\
7 & Beaver & 74.07 & 0.3906 & 0.33 & 261 & 303 \\
8 & Raccoon & 77.83 & 0.3656 & 0.329 & 270 & 318 \\
9 & Cat & 94.21 & 0.315 & 0.327 & 305 & 385 \\
10 & Dog & 103.6 & 0.2745 & 0.315 & 324 & 394 \\
11 & Tiger & 128.1 & 0.2221 & 0.282 & 382 & 604 \\
12 & Bear & 258.1 & 0.1102 & 0.25 & 595 & 1229 \\
\hline
\end{tabular}

The proposed FPA-based algorithm was simulated on $11 \mathrm{kV}, 123$ bus [5] and $11 \mathrm{kV}$, 51 bus [12] test systems. The results were compared with the PSO algorithm. For both the test systems, the base voltage was considered as $11 \mathrm{kV}$. The values of $K_{p}, K_{e}$, and $\gamma$ 
were considered as 2500 Rs./kW, $3.0 \mathrm{Rs} . / \mathrm{kWh}$, and 0.1 for the calculation of the cost function. The approximate conductor cost per kilogram was considered as $120 \mathrm{Rs} . / \mathrm{Kg}$ [55]. The network diagrams for 123 bus and 51 radial distribution systems are shown in Figures 6 and 7 .

The 123 bus and 51 bus test systems were simulated using MATLAB R2017a software. The optimal conductor selection results obtained with the proposed Flower Pollination Algorithm (FPA)-based methodology are shown in Table 2 for the 123 bus system and in Table 3 for the 51 bus system, respectively.

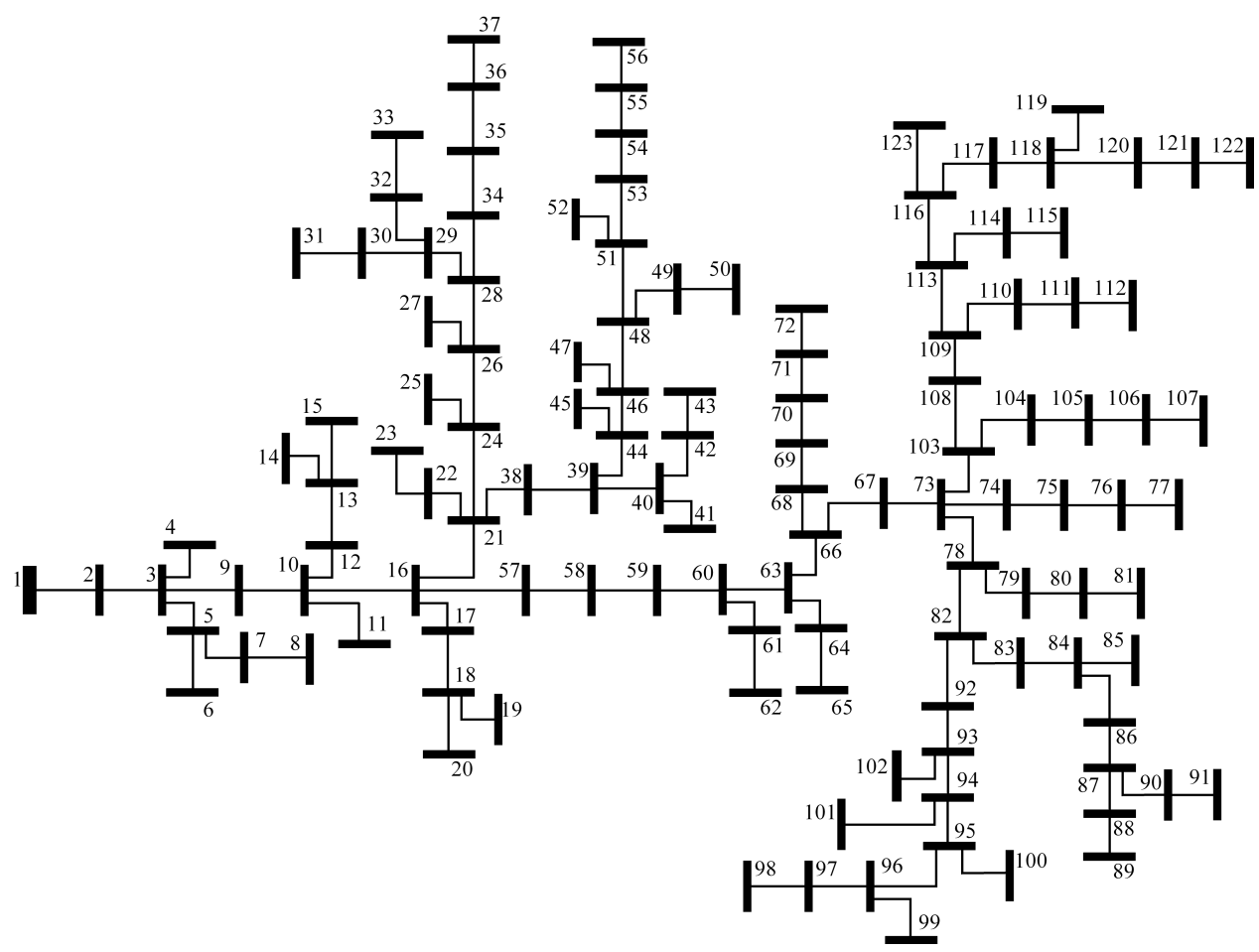

Figure 6. 123 bus radial distribution system.

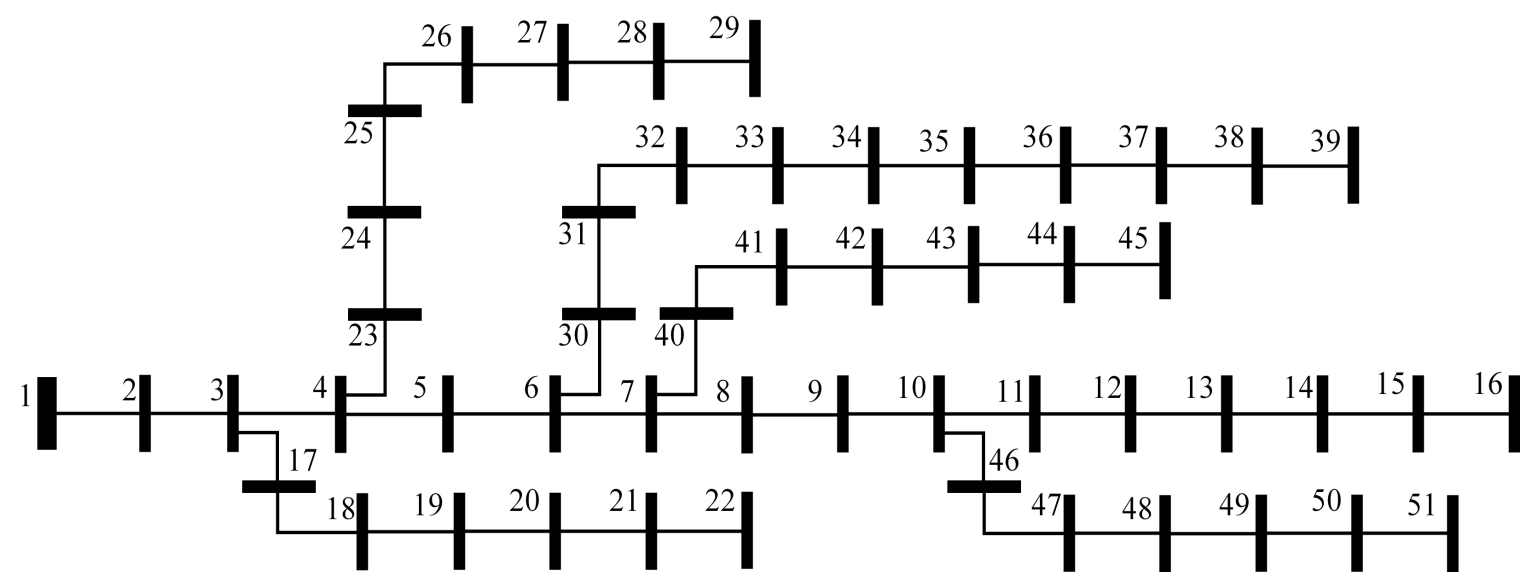

Figure 7.51 bus radial distribution system. 
Table 2. Optimum conductor selection for 123 bus system.

\begin{tabular}{|c|c|c|c|c|c|c|c|}
\hline \multirow{2}{*}{$\begin{array}{l}\text { Branch } \\
\text { Number }\end{array}$} & \multicolumn{3}{|c|}{ Conductor Type } & \multirow{2}{*}{$\begin{array}{l}\text { Branch } \\
\text { Number }\end{array}$} & \multicolumn{3}{|c|}{ Conductor Type } \\
\hline & Base Case & PSO & FPA & & Base Case & PSO & FPA \\
\hline 1 & Bear & Bear & Bear & 62 & Tiger & Bear & Bear \\
\hline 2 & Bear & Bear & Bear & 63 & Squirrel & Bear & Squirrel \\
\hline 3 & Squirrel & Bear & Squirrel & 64 & Squirrel & Squirrel & Bear \\
\hline 4 & Squirrel & Squirrel & Squirrel & 65 & Dog & Bear & Bear \\
\hline 5 & Squirrel & Bear & Beaver & 66 & Cat & Bear & Bear \\
\hline 6 & Squirrel & Squirrel & Raccoon & 67 & Squirrel & Bear & Weasel \\
\hline 7 & Squirrel & Squirrel & Squirrel & 68 & Squirrel & Bear & Bear \\
\hline 8 & Bear & Bear & Bear & 69 & Squirrel & Squirrel & Bear \\
\hline 9 & Bear & Bear & Bear & 70 & Squirrel & Squirrel & Rabbit \\
\hline 10 & Squirrel & Bear & Cat & 71 & Squirrel & Bear & Squirrel \\
\hline 11 & Squirrel & Bear & Weasel & 72 & Cat & Bear & Bear \\
\hline 12 & Squirrel & Squirrel & Squirrel & 73 & Squirrel & Bear & Bear \\
\hline 13 & Squirrel & Bear & Gopher & 74 & Squirrel & Squirrel & Tiger \\
\hline 14 & Squirrel & Squirrel & Beaver & 75 & Squirrel & Squirrel & Bear \\
\hline 15 & Bear & Bear & Bear & 76 & Squirrel & Squirrel & Ferret \\
\hline 16 & Squirrel & Squirrel & Weasel & 77 & Weasel & Bear & Bear \\
\hline 17 & Squirrel & Squirrel & Mink & 78 & Squirrel & Bear & Bear \\
\hline 18 & Squirrel & Squirrel & Bear & 79 & Squirrel & Squirrel & Squirrel \\
\hline 19 & Squirrel & Squirrel & Weasel & 80 & Squirrel & Squirrel & Gopher \\
\hline 20 & Ferret & Bear & Bear & 81 & Squirrel & Bear & Bear \\
\hline 21 & Squirrel & Bear & Raccoon & 82 & Squirrel & Squirrel & Mink \\
\hline 22 & Squirrel & Ferret & Gopher & 83 & Squirrel & Squirrel & Bear \\
\hline 23 & Squirrel & Squirrel & Dog & 84 & Squirrel & Squirrel & Rabbit \\
\hline 24 & Squirrel & Squirrel & Squirrel & 85 & Squirrel & Squirrel & Squirrel \\
\hline 25 & Squirrel & Bear & Mink & 86 & Squirrel & Bear & Rabbit \\
\hline 26 & Squirrel & Squirrel & Beaver & 87 & Squirrel & Squirrel & Squirrel \\
\hline 27 & Squirrel & Squirrel & Squirrel & 88 & Squirrel & Squirrel & Rabbit \\
\hline 28 & Squirrel & Squirrel & Weasel & 89 & Squirrel & Squirrel & Squirrel \\
\hline 29 & Squirrel & Squirrel & Mink & 90 & Squirrel & Squirrel & Raccoon \\
\hline 30 & Squirrel & Squirrel & Squirrel & 91 & Squirrel & Squirrel & Bear \\
\hline 31 & Squirrel & Squirrel & Weasel & 92 & Squirrel & Squirrel & Dog \\
\hline 32 & Squirrel & Squirrel & Squirrel & 93 & Squirrel & Bear & Dog \\
\hline 33 & Squirrel & Squirrel & Squirrel & 94 & Squirrel & Squirrel & Beaver \\
\hline
\end{tabular}


Table 2. Cont.

\begin{tabular}{|c|c|c|c|c|c|c|c|}
\hline \multirow{2}{*}{$\begin{array}{l}\text { Branch } \\
\text { Number }\end{array}$} & \multicolumn{3}{|c|}{ Conductor Type } & \multirow{2}{*}{$\begin{array}{l}\text { Branch } \\
\text { Number }\end{array}$} & \multicolumn{3}{|c|}{ Conductor Type } \\
\hline & Base Case & PSO & FPA & & Base Case & PSO & FPA \\
\hline 34 & Squirrel & Bear & Rabbit & 95 & Squirrel & Squirrel & Raccoon \\
\hline 35 & Squirrel & Bear & Gopher & 96 & Squirrel & Squirrel & Bear \\
\hline 36 & Squirrel & Squirrel & Cat & 97 & Squirrel & Bear & Squirrel \\
\hline 37 & Squirrel & Squirrel & Bear & 98 & Squirrel & Squirrel & Squirrel \\
\hline 38 & Squirrel & Bear & Bear & 99 & Squirrel & Squirrel & Squirrel \\
\hline 39 & Squirrel & Squirrel & Mink & 100 & Squirrel & Squirrel & Beaver \\
\hline 40 & Squirrel & Squirrel & Squirrel & 101 & Squirrel & Squirrel & Bear \\
\hline 41 & Squirrel & Gopher & Bear & 102 & Gopher & Bear & Bear \\
\hline 42 & Squirrel & Squirrel & Bear & 103 & Squirrel & Squirrel & Tiger \\
\hline 43 & Squirrel & Bear & Bear & 104 & Squirrel & Squirrel & Squirrel \\
\hline 44 & Squirrel & Bear & Bear & 105 & Squirrel & Bear & Squirrel \\
\hline 45 & Squirrel & Squirrel & Bear & 106 & Squirrel & Bear & Weasel \\
\hline 46 & Squirrel & Bear & Beaver & 107 & Squirrel & Bear & Tiger \\
\hline 47 & Squirrel & Bear & Bear & 108 & Squirrel & Bear & Bear \\
\hline 48 & Squirrel & Bear & Mink & 109 & Squirrel & Squirrel & Rabbit \\
\hline 49 & Squirrel & Bear & Squirrel & 110 & Squirrel & Squirrel & Bear \\
\hline 50 & Squirrel & Squirrel & Ferret & 111 & Squirrel & Bear & Weasel \\
\hline 51 & Squirrel & Squirrel & Ferret & 112 & Squirrel & Bear & Bear \\
\hline 52 & Squirrel & Squirrel & Bear & 113 & Squirrel & Ferret & Squirrel \\
\hline 53 & Squirrel & Bear & Squirrel & 114 & Squirrel & Squirrel & Squirrel \\
\hline 54 & Squirrel & Squirrel & Squirrel & 115 & Squirrel & Bear & Tiger \\
\hline 55 & Squirrel & Bear & Squirrel & 116 & Squirrel & Bear & Raccoon \\
\hline 56 & Tiger & Bear & Bear & 117 & Squirrel & Squirrel & Squirrel \\
\hline 57 & Tiger & Bear & Bear & 118 & Squirrel & Squirrel & Squirrel \\
\hline 58 & Tiger & Bear & Bear & 119 & Squirrel & Bear & Cat \\
\hline 59 & Tiger & Bear & Bear & 120 & Squirrel & Bear & Bear \\
\hline 60 & Squirrel & Squirrel & Bear & 121 & Squirrel & Squirrel & Squirrel \\
\hline 61 & Squirrel & Bear & Squirrel & 122 & Squirrel & Squirrel & Squirrel \\
\hline
\end{tabular}

Table 3. Optimum conductor selection for 51 bus system.

\begin{tabular}{|c|c|c|c|c|c|c|c|}
\hline \multirow{2}{*}{$\begin{array}{l}\text { Branch } \\
\text { Number }\end{array}$} & \multicolumn{3}{|c|}{ Conductor Type } & \multirow{2}{*}{$\begin{array}{l}\text { Branch } \\
\text { Number }\end{array}$} & \multicolumn{3}{|c|}{ Conductor Type } \\
\hline & Base Case & PSO & FPA & & Base Case & PSO & FPA \\
\hline 1 & Dog & Bear & Bear & 26 & Squirrel & Ferret & Beaver \\
\hline 2 & Dog & Bear & Bear & 27 & Squirrel & Squirrel & Squirrel \\
\hline 3 & Dog & Bear & Bear & 28 & Squirrel & Bear & Ferret \\
\hline 4 & Dog & Bear & Bear & 29 & Rabbit & Squirrel & Tiger \\
\hline 5 & Mink & Bear & Bear & 30 & Rabbit & Dog & Dog \\
\hline 6 & Mink & Bear & Bear & 31 & Rabbit & Dog & Cat \\
\hline 7 & Mink & Bear & Bear & 32 & Rabbit & Racoon & Beaver \\
\hline 8 & Mink & Bear & Bear & 33 & Rabbit & Dog & Racoon \\
\hline 9 & Squirrel & Dog & Dog & 34 & Rabbit & Mink & Squirrel \\
\hline 10 & Squirrel & Bear & Dog & 35 & Rabbit & Bear & Beaver \\
\hline 11 & Squirrel & Dog & Racoon & 36 & Rabbit & Squirrel & Squirrel \\
\hline 12 & Squirrel & Dog & Rabbit & 37 & Rabbit & Weasel & Gopher \\
\hline 13 & Squirrel & Squirrel & Dog & 38 & Rabbit & Squirrel & Gopher \\
\hline 14 & Squirrel & Mink & Racoon & 39 & Squirrel & Bear & Dog \\
\hline
\end{tabular}


Table 3. Cont.

\begin{tabular}{|c|c|c|c|c|c|c|c|}
\hline \multirow{2}{*}{$\begin{array}{l}\text { Branch } \\
\text { Number }\end{array}$} & \multicolumn{3}{|c|}{ Conductor Type } & \multirow{2}{*}{$\begin{array}{l}\text { Branch } \\
\text { Number }\end{array}$} & \multicolumn{3}{|c|}{ Conductor Type } \\
\hline & Base Case & PSO & FPA & & Base Case & PSO & FPA \\
\hline 15 & Squirrel & Squirrel & Squirrel & 40 & Squirrel & Dog & Dog \\
\hline 16 & Squirrel & Dog & Dog & 41 & Squirrel & Dog & Rabbit \\
\hline 17 & Squirrel & Bear & Rabbit & 42 & Squirrel & Mink & Mink \\
\hline 18 & Squirrel & Dog & Cat & 43 & Squirrel & Ferret & Rabbit \\
\hline 19 & Squirrel & Mink & Ferret & 44 & Squirrel & Squirrel & Ferret \\
\hline 20 & Squirrel & Ferret & Squirrel & 45 & Squirrel & Dog & Dog \\
\hline 21 & Squirrel & Squirrel & Rabbit & 46 & Squirrel & Squirrel & Ferret \\
\hline 22 & Squirrel & Dog & Tiger & 47 & Squirrel & Mink & Rabbit \\
\hline 23 & Squirrel & Dog & Beaver & 48 & Squirrel & Rabbit & Squirrel \\
\hline 24 & Squirrel & Mink & Squirrel & 49 & Squirrel & Bear & Ferret \\
\hline 25 & Squirrel & Squirrel & Mink & 50 & Squirrel & Squirrel & Squirrel \\
\hline
\end{tabular}

The performance comparisons with FPA for both the distribution systems are shown in Tables 4 and 5 . Tables 4 and 5 show that the real power loss reduction and minimum voltage improvement was much better in the case of the FPA algorithm than the PSO algorithm. Furthermore, from Table 6, it can be observed that with the proposed FPA algorithm, the reconductoring cost is much less, and the annual energy savings and economic savings are better for both the distribution systems considered.

Table 4. Comparison of voltage min (p.u).

\begin{tabular}{ccccccc}
\hline \multicolumn{3}{c}{ 123 Bus } & \multicolumn{3}{c}{ 51 Bus } \\
\hline Load Factor & 0.4 & 0.7 & 1.0 & 0.4 & 0.7 & 1.0 \\
\hline Base Case & 0.9930 & 0.9877 & 0.9824 & 0.9659 & 0.9390 & 0.9107 \\
\hline PSO & 0.9949 & 0.9911 & 0.9872 & 0.9851 & 0.9737 & 0.9621 \\
\hline FPA & 0.9956 & 0.9923 & 0.9890 & 0.9852 & 0.9739 & 0.9623 \\
\hline
\end{tabular}

Table 5. Comparison of real power losses (kW).

\begin{tabular}{ccccccc}
\hline & \multicolumn{3}{c}{ 123 Bus } & \multicolumn{3}{c}{ 51 Bus } \\
\hline Load Factor & 0.4 & 0.7 & 1.0 & 0.4 & 0.7 & 1.0 \\
\hline Base Case & 7.83 & 24.17 & 49.73 & 19.20 & 61.07 & 129.81 \\
\hline PSO & 4.28 & 13.19 & 27.08 & 6.38 & 19.88 & 41.31 \\
\hline FPA & 3.91 & 12.04 & 24.71 & 6.26 & 19.51 & 40.52 \\
\hline
\end{tabular}

Table 6. Annual savings comparison.

\begin{tabular}{ccccc}
\hline & \multicolumn{2}{c}{ 123 Bus System } & \multicolumn{2}{c}{ 51 Bus System } \\
\cline { 2 - 5 } & PSO & FPA & PSO & FPA \\
\hline Conductor Cost (Rs) & $1,482,368$ & $1,339,892$ & $4,344,009$ & $3,664,850$ \\
\hline Annual Energy Savings (kWh) & 108,566 & 119,924 & 416,129 & 419,867 \\
\hline Energy savings/day (kWh) & 297.44 & 328.56 & 1140.08 & 1150.32 \\
\hline Annual Economical Savings (Rs) & 208,204 & 264,940 & 959,392 & $1,052,353$ \\
\hline
\end{tabular}

The allocation of energy savings per day and per slot for EV load for 123 bus and 51 bus test systems are shown in Tables 7 and 8 . As shown in the tables, two case studies were developed for distributing the EV charging load. Case-1 consists of distributing the EV 
charging load such that $25 \%$ of the available energy savings are allocated at 0.4 load factor, and the remaining energy savings are allocated at 0.7 load factor. In Case-2, the available energy savings are equally distributed between 0.4 and 0.7 load factors. Since most of the EV batteries require $8 \mathrm{~h}$ for charging from $20 \%$ to $90 \%$ state of charge; each charging slot duration $\left(T_{E V}\right)$ was considered as $4 \mathrm{~h}$ duration. The additional real power loss $\left(R P L_{L F}^{E V \max }\right)$ with EV load load and the total real power loss $\left(R P L_{L F}^{E V R C}\right)$ permitted with EV load was calculated as described in Section 6.2.

Table 7. Energy savings allocation with EV load for 123 bus.

\begin{tabular}{lcccc}
\hline 123 Bus & \multicolumn{2}{c}{$\begin{array}{c}\text { Case-1 } \\
\mathbf{( 2 5 - 7 5 \% )}\end{array}$} & \multicolumn{2}{c}{$\begin{array}{c}\text { Case-2 } \\
\mathbf{( 5 0 - 5 0 \% )}\end{array}$} \\
\hline Load Factor & 0.4 & 0.7 & 0.4 & 0.7 \\
\hline Energy Savings Available/day (kWh) & 41.07 & 123.21 & 82.14 & 82.14 \\
\hline Energy Savings Available/slot (kWh) & 20.535 & 61.605 & 41.07 & 41.07 \\
\hline Additional Real power loss with EV load (kW) & 5.13 & 15.4 & 10.26 & 10.26 \\
\hline Real power loss without EV load (kW) & 3.91 & 12.04 & 3.91 & 12.04 \\
\hline Total loss permitted with EV load (kW) & 9.04 & 27.44 & 14.17 & 22.3 \\
\hline Actual loss with EV load (kW) & 9.04 & 27.44 & 14.17 & 22.3 \\
\hline Voltage min (p.u) & 0.9938 & 0.9891 & 0.9924 & 0.9901 \\
\hline
\end{tabular}

Table 8. Energy savings allocation with EV load for 51 bus.

\begin{tabular}{lllll}
\hline $\mathbf{5 1}$ Bus & \multicolumn{2}{c}{$\begin{array}{c}\text { Case-1 } \\
\mathbf{( 2 5 - 7 5 \% )}\end{array}$} & \multicolumn{2}{c}{$\begin{array}{c}\text { Case-2 } \\
\mathbf{( 5 0 - 5 0 \% )}\end{array}$} \\
\hline Load Factor & 0.4 & 0.7 & 0.4 & 0.7 \\
\hline Energy Savings Available/day (kWh) & 143.79 & 431.37 & 287.58 & 287.58 \\
\hline Energy Savings Available/slot (kWh) & 71.895 & 215.685 & 143.79 & 143.79 \\
\hline Additional Real power loss with EV load (kW) & 17.97 & 53.92 & 35.94 & 35.94 \\
\hline Real power loss without EV load $(\mathrm{kW})$ & 6.26 & 19.51 & 6.26 & 19.51 \\
\hline Total loss permitted with EV load $(\mathrm{kW})$ & 24.23 & 73.43 & 42.2 & 54.45 \\
\hline Actual loss with EV load (kW) & 24.23 & 73.43 & 42.2 & 54.45 \\
\hline Voltage min (p.u) & 0.9736 & 0.9536 & 0.966 & 0.9594 \\
\hline
\end{tabular}

In this work, the minimum EV battery capacity was considered as $1 \mathrm{kWh}$, and to charge the battery completely in $4 \mathrm{~h}, 0.25 \mathrm{~kW}$ active power was drawn from the charger. Since most EV chargers operate at a 0.95 power factor, the charger derives a reactive power of $0.082 \mathrm{kVAr}$ during battery charging. Figures 8-11 show the allocation of EV charging load for both cases. The permissible EV charging load at each node is obtained based on the allowable power loss shown in Tables 7 and 8 and the heuristic algorithm presented in Section 7 . 

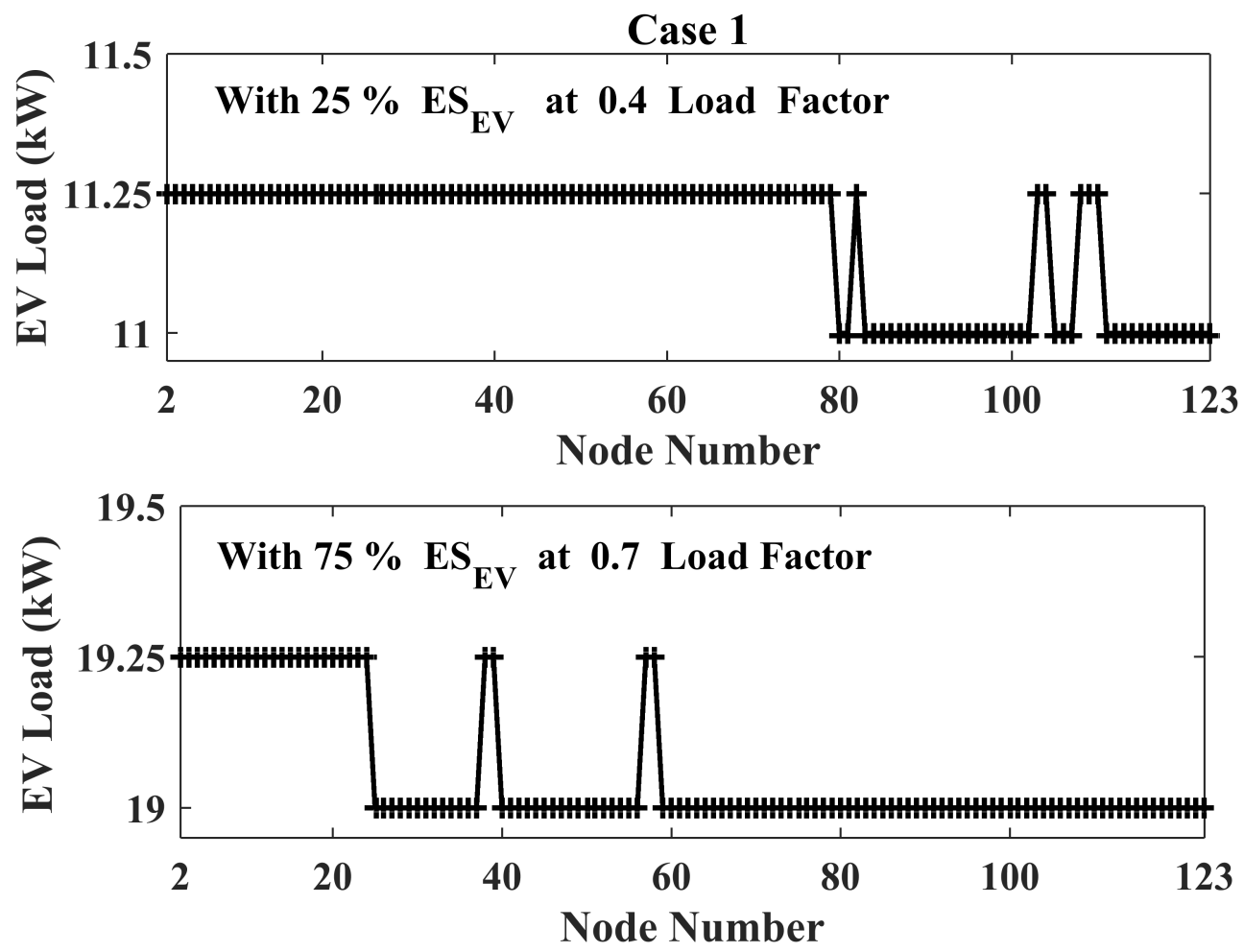

Figure 8. EV load allocation for 123 bus system for Case-1.

For instance, in case- 1 at a 0.4 load factor for 123 bus system, the EV charging load at each node is the real power increased in steps of $0.25 \mathrm{~kW}$, and the reactive power at 0.95 power factor until the total real power loss just exceeded $9.04 \mathrm{~kW}$ as mentioned in Table 7 . The EV charging load at each node was then decreased by $0.25 \mathrm{~kW}$ until the total power loss equals $9.04 \mathrm{~kW}$. This is evident in Figure 8 at a 0.4 load factor, wherein the maximum EV charging load at each node was either $11.25 \mathrm{~kW}$ or $11 \mathrm{~kW}$. Similarly, it can be observed from Figures 9-11 that the maximum EV charging load per node fluctuates by $0.25 \mathrm{~kW}$.
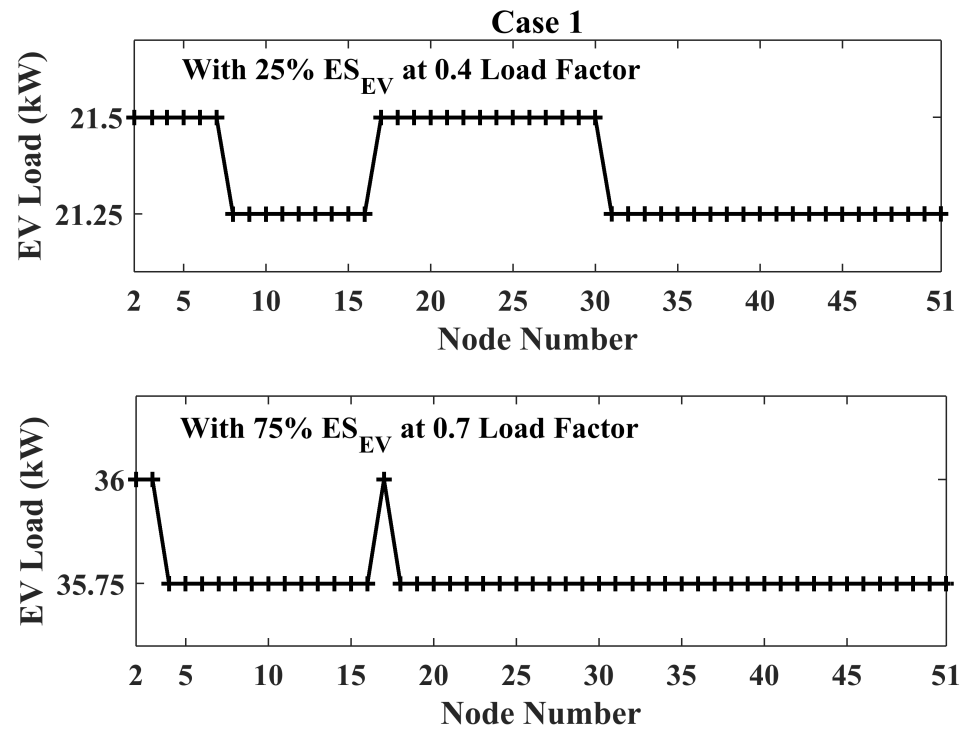

Figure 9. EV load allocation for 51 bus system for Case-1. 
Case 2
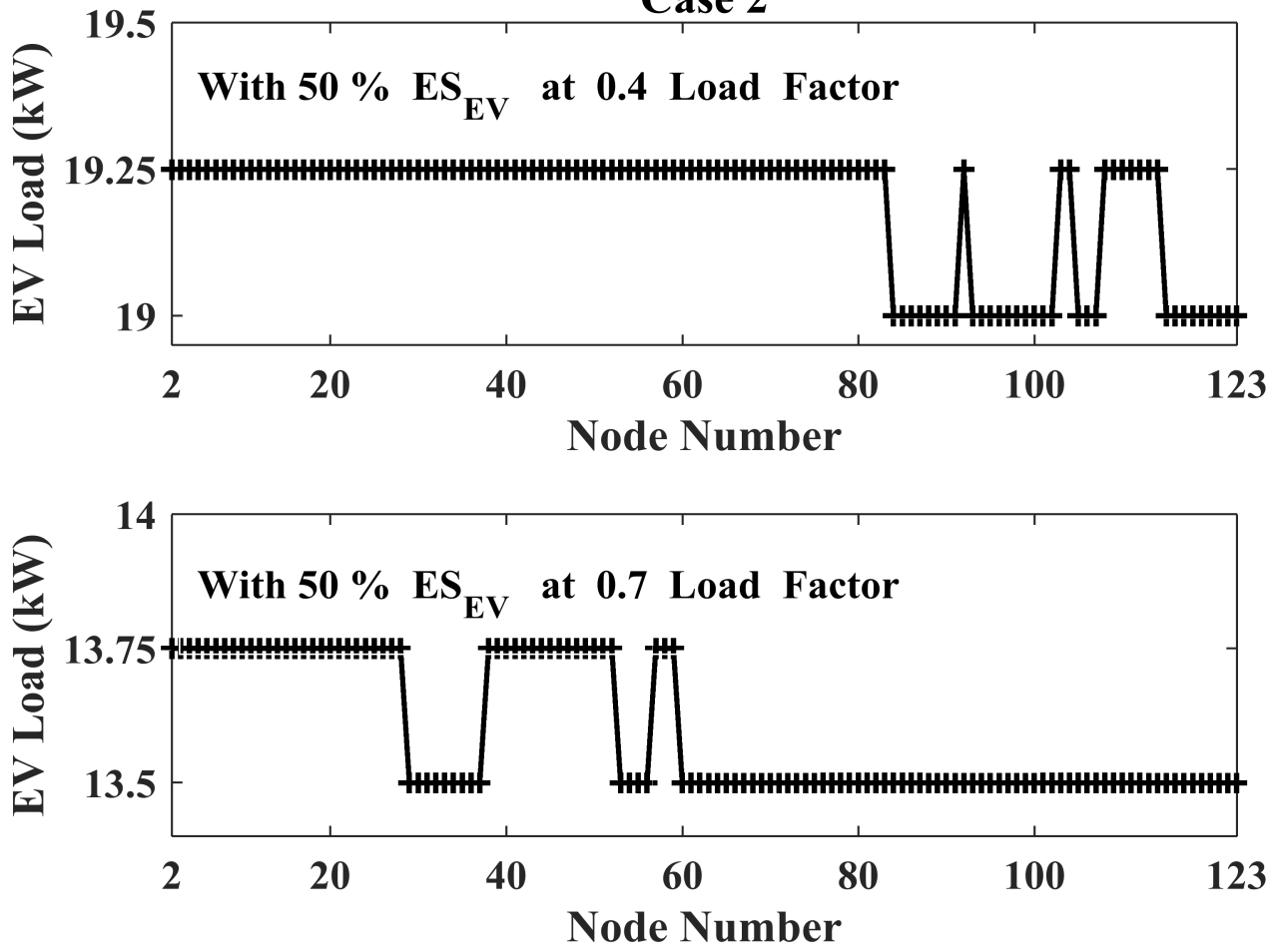

Figure 10. EV load allocation for 123 bus system for Case-2.
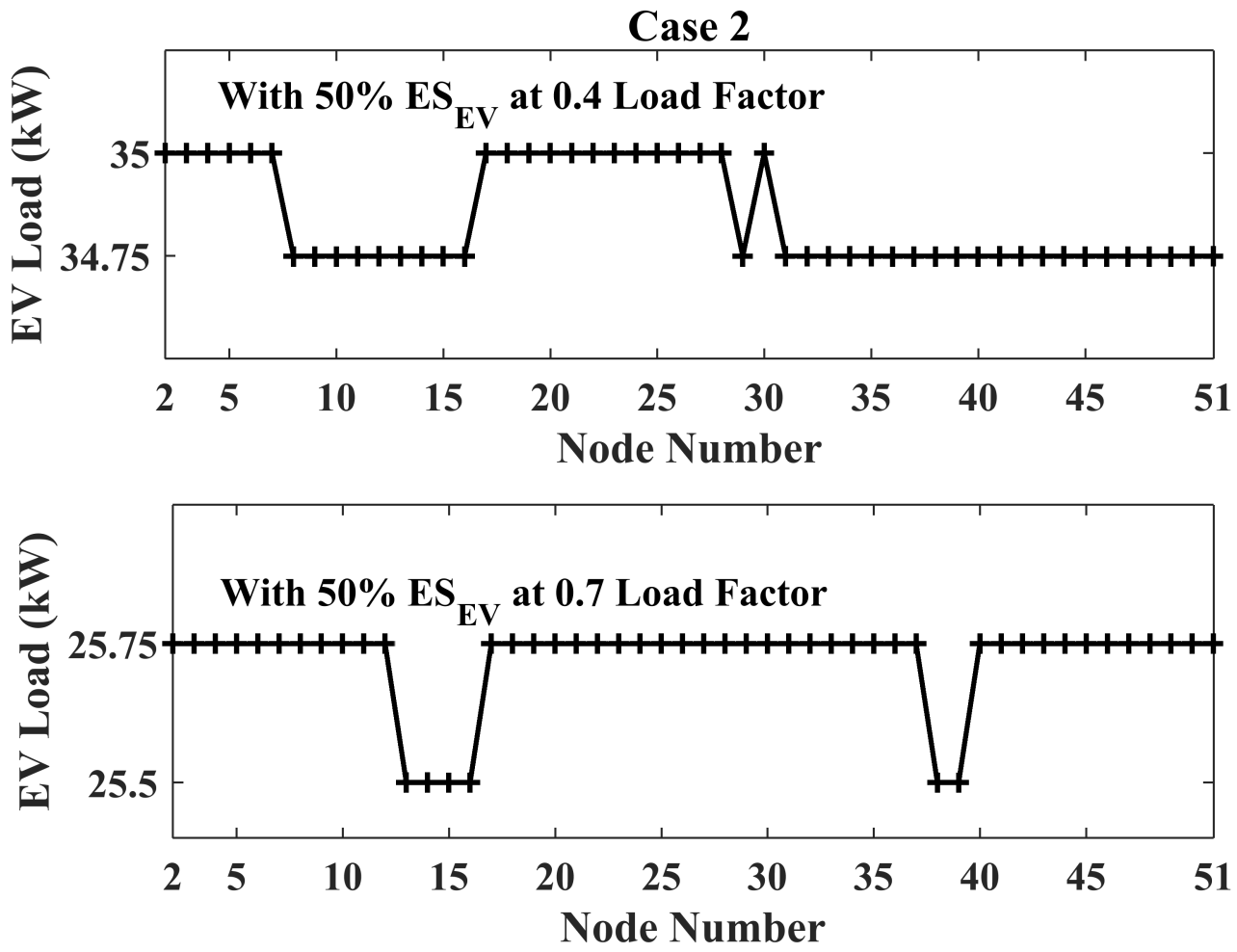

Figure 11. EV load allocation for 51 bus system for Case-2.

In this work, the requirements of EV charging load at residential locations are analyzed considering three different types of electric vehicles commonly used for transportation. They are Mahindra e2oPlus Electric Car with a battery capacity of $10.08 \mathrm{kWh}$, Revolt 
RV400 Electric Bike with a battery capacity of $3.24 \mathrm{kWh}$, and Okinawa R30 Electric Scooter with $1.25 \mathrm{kWh}$. All three types of EVs can be charged from $20 \%$ to $90 \%$ in $4 \mathrm{~h}$. From Tables 9 and 10 , it can be observed that the number of EVs at each node varies based on the maximum permissible EV charging load per node depicted in Figures 8-11.

Table 9. Number of EVs charged per slot for 123 bus.

\begin{tabular}{|c|c|c|c|c|c|c|}
\hline 123 Bus & $\begin{array}{c}\text { Load } \\
\text { Factor }\end{array}$ & $\begin{array}{c}\text { Number of } \\
\text { Nodes }\end{array}$ & $\begin{array}{c}\text { EV Load/ } \\
\text { Node }\end{array}$ & $\begin{array}{c}\mathbf{N}_{\text {Cars }} / \text { slot/ } \\
\text { Node }\end{array}$ & $\begin{array}{c}\mathbf{N}_{\text {Bikes }} / \text { slot/ } \\
\text { Node }\end{array}$ & $\begin{array}{c}\mathbf{N}_{\text {Scooters }} / \text { slot/ } \\
\text { Node }\end{array}$ \\
\hline \multirow{4}{*}{ Case-1 } & \multirow{2}{*}{0.4} & 84 & 11.25 & 4 & 1 & 2 \\
\hline & & 38 & 11 & 4 & 1 & 1 \\
\hline & \multirow{2}{*}{0.7} & 27 & 19.25 & 7 & 2 & 1 \\
\hline & & 95 & 19 & 7 & 2 & 0 \\
\hline \multirow{4}{*}{ Case -2} & \multirow{2}{*}{0.4} & 92 & 19.25 & 7 & 2 & 1 \\
\hline & & 30 & 19 & 7 & 2 & 0 \\
\hline & \multirow{2}{*}{0.7} & 45 & 13.75 & 5 & 1 & 2 \\
\hline & & 77 & 13.5 & 5 & 1 & 1 \\
\hline
\end{tabular}

Table 10. Number of EVs charged per slot for 51 bus.

\begin{tabular}{|c|c|c|c|c|c|c|}
\hline 51 Bus & $\begin{array}{l}\text { Load } \\
\text { Factor }\end{array}$ & $\begin{array}{l}\text { Number of } \\
\text { Nodes }\end{array}$ & $\begin{array}{l}\text { EV Load/ } \\
\text { Node }\end{array}$ & $\begin{array}{c}\mathbf{N}_{\text {Cars }} / \text { slot/ } \\
\text { Node }\end{array}$ & $\begin{array}{c}\mathbf{N}_{\text {Bikes }} / \text { slot/ } \\
\text { Node }\end{array}$ & $\begin{array}{c}\mathbf{N}_{\text {Scooters }} / \text { slot } \\
\text { Node }\end{array}$ \\
\hline \multirow{4}{*}{ Case-1 } & \multirow{2}{*}{0.4} & 20 & 21.5 & 8 & 2 & 0 \\
\hline & & 30 & 21.25 & 8 & 1 & 2 \\
\hline & \multirow{2}{*}{0.7} & 3 & 36 & 14 & 1 & 1 \\
\hline & & 47 & 35.75 & 14 & 1 & 0 \\
\hline \multirow{4}{*}{ Case-2 } & \multirow{2}{*}{0.4} & 19 & 35 & 14 & 0 & 0 \\
\hline & & 31 & 34.75 & 13 & 3 & 0 \\
\hline & \multirow{2}{*}{0.7} & 44 & 25.75 & 10 & 1 & 0 \\
\hline & & 6 & 25.5 & 10 & 0 & 2 \\
\hline
\end{tabular}

Tables 11 and 12 present the total number of electric vehicles that can be charged per day for both the test systems. One crucial aspect that has to be observed is that in Case-1, more electric vehicles can be charged during the duration when the load factor is 0.7 . This is because $75 \%$ of the considered energy savings are allocated to 0.7 load factor, which facilitates a significant increase in power losses, thereby allowing a significant increase in EV charging load at each node. On the other hand, in Case-2, more electric vehicles can be charged during the duration when the load factor is 0.4 since the considered energy savings are equally distributed between both the load factors. 
Table 11. Number of EVs charged per day for 123 bus.

\begin{tabular}{lllll}
\hline \multirow{2}{*}{123 Bus } & \multicolumn{2}{l}{ Load Factor } & \multirow{2}{*}{ Total NO of Vehicles } \\
\cline { 2 - 5 } Case -1 & $\mathbf{0 . 4}$ & $\mathbf{0 . 7}$ & \\
\hline & $\mathrm{N}_{\text {Cars }} /$ day & 976 & 1708 & 2684 \\
\cline { 2 - 5 } & $\mathrm{N}_{\text {Bikes }} /$ day & 244 & 488 & 732 \\
\cline { 2 - 5 } Case -2 & $\mathrm{~N}_{\text {Scooters }} /$ day & 412 & 54 & 466 \\
\cline { 2 - 5 } & $\mathrm{N}_{\text {Cars }} /$ day & 1708 & 1220 & 2928 \\
\cline { 2 - 5 } & $\mathrm{N}_{\text {Bikes }} /$ day & 488 & 244 & 732 \\
\cline { 2 - 5 } & $\mathrm{N}_{\text {Scooters }} /$ day & 184 & 334 & 518 \\
\hline
\end{tabular}

Table 12. Number of EVs charged per day for 51 bus.

\begin{tabular}{lllll}
\hline & \multirow{2}{*}{$\mathbf{5 1}$ Bus } & \multicolumn{2}{l}{ Load Factor } & \multirow{2}{*}{ Total NO of EVs } \\
\cline { 3 - 5 } & & $\mathbf{0 . 4}$ & $\mathbf{0 . 7}$ & \\
\hline \multirow{2}{*}{ Case -1} & $\mathrm{~N}_{\text {cars }} /$ day & 800 & 1400 & 2200 \\
\cline { 2 - 5 } & $\mathrm{N}_{\text {Bikes }} /$ day & 140 & 100 & 240 \\
\cline { 2 - 5 } Case -2 & $\mathrm{~N}_{\text {Scooters }} /$ day & 120 & 6 & 126 \\
\cline { 2 - 5 } & $\mathrm{N}_{\text {cars }} /$ day & 1338 & 1000 & 2338 \\
\cline { 2 - 5 } & $\mathrm{N}_{\text {Bikes }} /$ day & 186 & 88 & 274 \\
\cline { 2 - 5 } & $\mathrm{N}_{\text {Scooters }} /$ day & 0 & 24 & 24 \\
\hline
\end{tabular}

The total EV charging load injection per slot for Case-1 and Case- 2 is presented in Tables 13 and 14 for the 123 bus system and 51 bus system, respectively. From the tables, it is clear that in Case-1, the percentage of EV load injection is more significant at 0.7 load factor duration when compared to 0.4 load factor duration. In Case-2, the percentage of EV load injection is greater at 0.4 load factor duration when compared to 0.7 load factor duration. Therefore, by allocating $50 \%$ of the energy savings obtained through reconductoring and allowing the losses to increase, a significant amount of EV charging load can be injected into the distribution system without violating the minimum voltage limits for both the test systems.

Table 13. EV load charging capacity per day for 123 bus.

\begin{tabular}{|c|c|c|c|c|}
\hline \multirow[b]{2}{*}{123 Bus } & \multicolumn{2}{|c|}{ Case-1 } & \multicolumn{2}{|c|}{ Case-2 } \\
\hline & $\begin{array}{l}0.4 \text { Load } \\
\text { Factor }\end{array}$ & $\begin{array}{l}0.7 \text { Load } \\
\text { Factor }\end{array}$ & $\begin{array}{l}0.4 \text { Load } \\
\text { Factor }\end{array}$ & $\begin{array}{l}0.7 \text { Load } \\
\text { Factor }\end{array}$ \\
\hline $\begin{array}{l}\text { EV load injection/slot } \\
(\mathrm{kW})\end{array}$ & 1363 & 2324.75 & 2341 & 1658.25 \\
\hline EV load injection/slot (\%) & 27.28 & 46.43 & 46.86 & 33.19 \\
\hline $\begin{array}{l}\text { EV load charging capacity/day } \\
(\mathrm{kWh})\end{array}$ & \multicolumn{2}{|c|}{29,502} & \multicolumn{2}{|c|}{31,994} \\
\hline $\begin{array}{l}\text { EV load charging } \\
\text { capacity/day }(\%)\end{array}$ & \multicolumn{2}{|c|}{35.15} & \multicolumn{2}{|c|}{38.12} \\
\hline
\end{tabular}


Table 14. EV load charging capacity per day for 51 bus.

\begin{tabular}{lcccc}
\hline \multirow{2}{*}{ 51 Bus } & \multicolumn{2}{c}{ Case-1 } & \multicolumn{2}{c}{ Case-2 } \\
\cline { 2 - 5 } & $\begin{array}{c}\text { 0.4 Load } \\
\text { Factor }\end{array}$ & $\begin{array}{c}\mathbf{0 . 7} \text { Load } \\
\text { Factor }\end{array}$ & $\begin{array}{c}\text { 0.4 Load } \\
\text { Factor }\end{array}$ & $\begin{array}{c}\mathbf{0 . 7} \text { Load } \\
\text { Factor }\end{array}$ \\
\hline $\begin{array}{l}\text { EV load injection/slot } \\
(\mathrm{kW})\end{array}$ & 1067.50 & 1788.25 & 1742.25 & 1286.00 \\
\hline EV load injection/slot (\%) & 43.34 & 72.61 & 70.74 & 52.21 \\
\hline $\begin{array}{l}\text { EV load charging capacity/day } \\
(\mathrm{kWh})\end{array}$ & \multicolumn{2}{c}{22,846} & \multicolumn{2}{c}{24,226} \\
\hline $\begin{array}{l}\text { EV load charging } \\
\text { capacity/day (\%) }\end{array}$ & \multicolumn{2}{c}{55.21} & & \\
\hline
\end{tabular}

From Tables 13 and 14, it can be seen that the maximum possible EV charging load per day was 31,994 kWh and 24,226 kWh for 123 bus and 51 bus systems, respectively. The Battery Energy Storage Systems (BESS) cost was approximately Rs 22,000/kWh $(\$ 300 / \mathrm{kWh})$ [56] and requires huge capital investment for managing EV load per day, which is practically impossible. Moreover, the required energy is difficult to manage from solar PV systems at residential locations. Therefore, it is more economical to reinforce the distribution network with network reconductoring and supply the required power for managing EV load from the substation.

Figure 12 shows the EV charging load at each node for both the test systems, considering the allocation of $100 \%$ of the available energy savings to either of the load factor durations. It can be observed from the figures that at a 0.4 load factor, more EV load can be allocated compared to that 0.7 load factor.
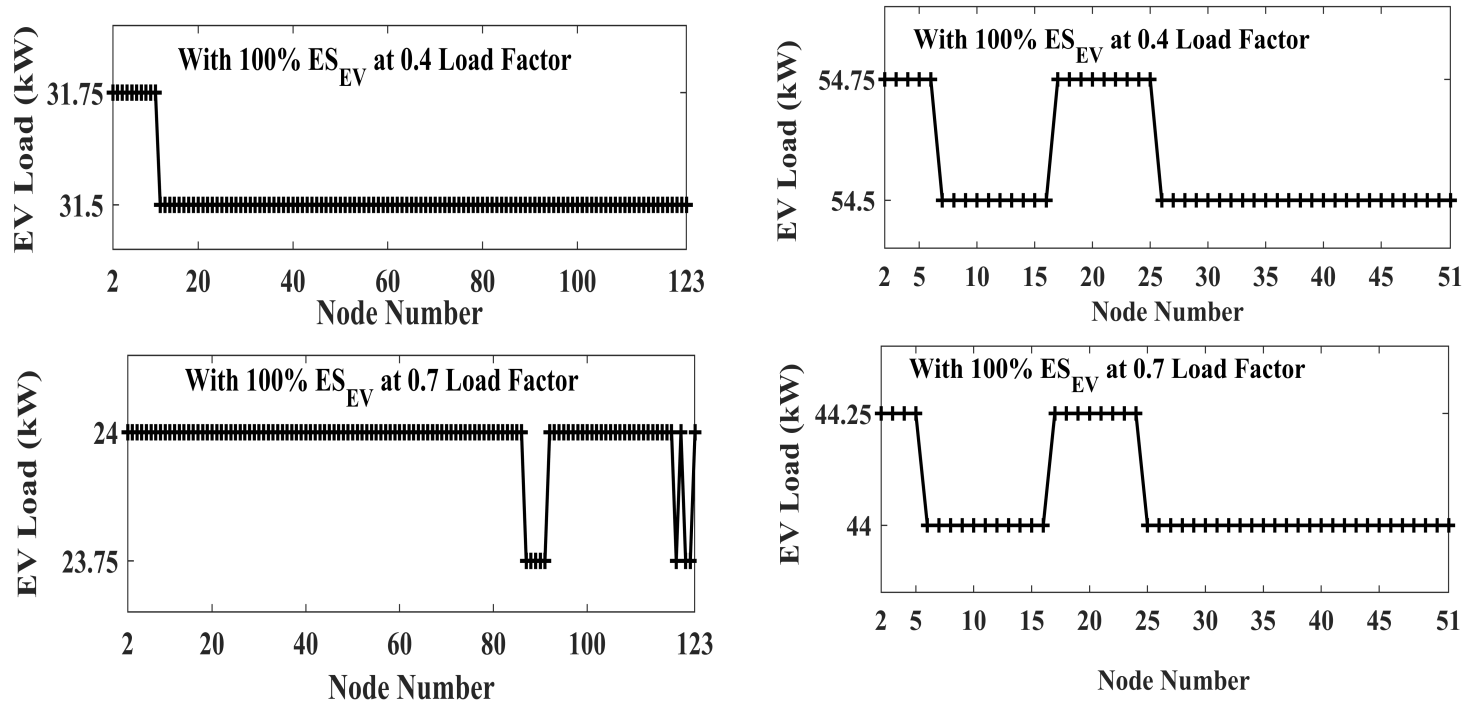

(a)

(b)

Figure 12. EV load with $100 \%$ energy savings. (a) 123 bus system. (b) 51 bus system.

The maximum solar PV generation is primarily available during the afternoon hours and can be used to support peak load during the daytime. From Figure 13, it can be observed that with solar PV injection minimum voltage profile can be improved and power loss can be reduced. 


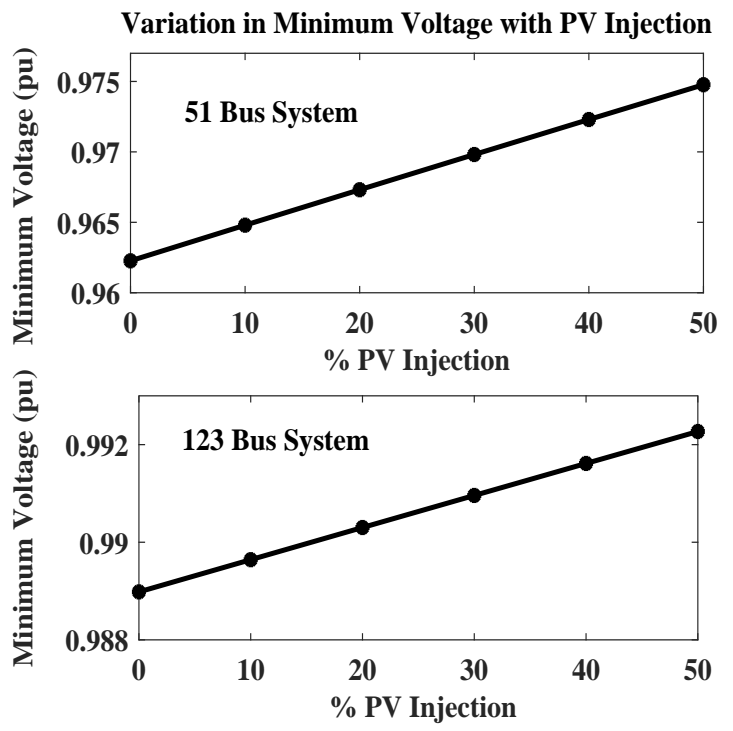

(a)
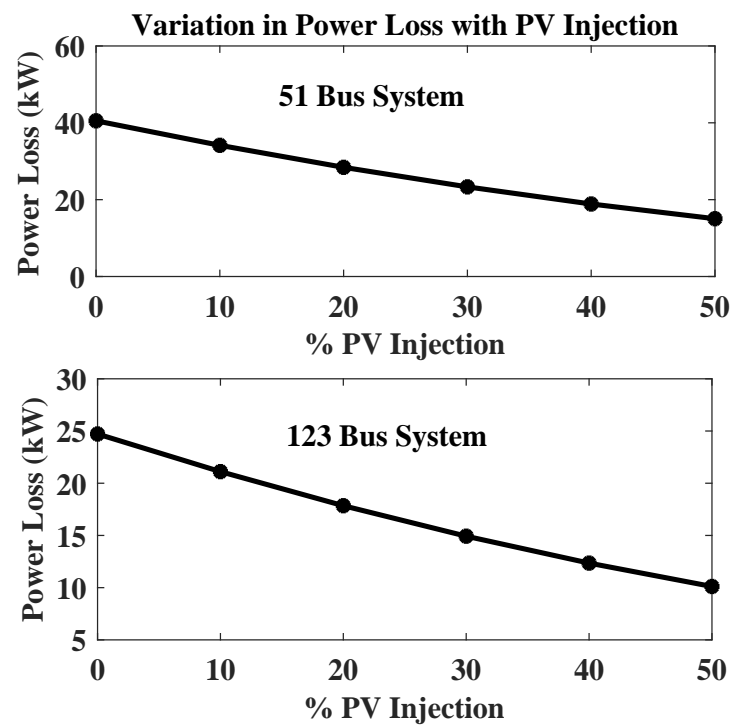

(b)

Figure 13. Performance with PV injection. (a) Minimum voltage. (b) Real power loss.

It has to be noted that due to the significant increase in EV load, utilities are required to improve the capacity of the distribution transformers. On the other hand, if it is expensive to upgrade the distribution transformers, the distribution transformer overload problems can be mitigated by limiting the total load on the substation during off-peak hours to the base case peak value. The total load on the substation includes the distribution system load and the EV charging load. In the proposed work, the authors assumed that the distribution transformers were upgraded to meet the EV charging load requirement. Network reconfiguration techniques can be applied along with reconductoring to further minimize the real power losses to avoid transformer overloads. In addition, the burden on the distribution transformers can be minimized by the optimal placement of shunt capacitor banks and distributed generators along with network reconductoring and reconfiguration techniques.

\section{Conclusions}

This article proposed a two-stage methodology for optimum allocation of EV chargers at residential locations utilizing the energy savings gained by the optimal network reconductoring of distribution systems. In the first stage, the Flower Pollination Algorithm (FPA)-based technique was used for the optimum network reconductoring of radial distribution systems for minimizing the annual energy losses at the optimum conductor cost. The distribution system voltage profile was improved, and the real power losses were reduced to much better values with the proposed FPA-based methodology compared to the base case and PSO-based algorithms. Compared to the PSO-based approach, the annual energy and economic savings were improved to a considerably high value at the optimum conductor cost with the proposed optimum network reconductoring approach.

In the next stage, the EV load allocation at each node of the distribution system was carried out using a simple heuristic methodology utilizing the part of the total annual energy savings gained the network reconductoring. The total annual energy savings were calculated considering the distribution load at three different load factors during a day. The simulation results show that the maximum EV load can be allocated when the energy savings are shared equally between off-peak hours at lower load factors during morning and evening peak hours rather than considering more energy savings during evening peak hours. The maximum EV load that can be accommodated at each node of the distribution system satisfying voltage and current constraints was calculated and was considerably high at a lower load factor considered for the same energy savings. The EV charging load was distributed among the three most commonly used electric vehicles by 
the consumers at residential locations, i.e., cars, bikes, and scooters. It was observed that a reinforced distribution network with optimum network reconductoring can satisfy the charging requirements of a large number of electric vehicles.

The solar PV energy available at residential locations is insufficient for large-scale EV load penetration. Moreover, the capital investment required for installing a battery energy storage system is very high to manage the huge EV charging load for residential consumers. Hence, it is more economical to enhance the distribution system performance using network reconductoring and supplying the required EV load from the substation. Furthermore, urban distribution systems are required to accommodate significant EV charging load at residential locations in the future. Therefore, the distribution systems must be reinforced through network reconductoring and upgradation of distribution transformers to support large EV charging load. Smart grid technologies can be effectively used for commercial EV charging stations that cater to commercial and public transportation such as buses, trucks, taxies, and heavy vehicles. Additional case studies incorporating smart grid technologies can be considered as future work for optimal sizing and allocation of commercial charging stations with the support of energy storage systems, renewable energy sources, and demand response techniques.

Author Contributions: Conceptualization, P.G., S.R.G. and K.J.; methodology, P.G., S.R.G., K.J., D.D., W.S, P.S. and J.M.G.; software, P.G., S.R.G. and K.J.; validation, D.D., W.S., P.S. and J.M.G.; formal analysis, P.G., S.R.G. and K.J.; writing—original draft preparation, P.G. and S.R.G.; writing—review and editing, P.G., D.D., W.S., P.S. and J.M.G. All authors have read and agreed to the published version of the manuscript.

Funding: This research received no external funding.

Conflicts of Interest: The authors declare no conflict of interest.

\section{Abbreviations}

The following abbreviations are used in this manuscript:

$\begin{array}{ll}A I P & \text { Annual installment payment } \\ P L_{i} & \text { Active power with EV load at } i \text { th node } \\ A E S C & \text { Annual energy savings cost } \\ Q L_{i} & \text { Reactive power with EV load at } i \text { th node } \\ A P L C & \text { Annual peak loss savings cost } \\ P E V(t) & \text { EV battery Charging power } \\ A E C O N S & \text { Annual economics savings } \\ P E V C P & \text { Constant power mode EV load power } \\ N B & \text { Number of branches in the distribution network } \\ P E V C V & \text { Constant voltage mode EV load power } \\ N & \text { Number of years of installment } \\ E S_{E V} & \text { Energy savings for EV charging per day } \\ M & \text { Mantegna algorithm } \\ T_{L F} & \text { Annual distribution load h at LF } \\ L F & \text { Distribution load factor } \\ P E V V_{\text {min }} & \text { Minimum EV real power load } \\ C_{i} & \text { Cost of the conductor in } i \text { th branch in Rs. } / \mathrm{km}\end{array}$




$\begin{array}{ll}Q E V_{\text {min }}^{E V} & \text { Minimum EV reactive power load } \\ B E S(t) & \text { Instantaneous battery storage capacity } \\ P E V_{\text {car }}^{\text {max }} & \text { Maximum power drawn by electric car } \\ I_{\text {rate }} & \text { Rate of interest } \\ P E V_{\text {bike }}^{\text {max }} & \text { Maximum power drawn by electric bike } \\ I_{j, L F} & \text { Current in branch } \mathrm{j} \text { for the load factor LF } \\ P E V_{\text {scooter }}^{\text {max }} & \text { Maximum power drawn by electric scooter } \\ I_{\text {max }, k} & \text { Max current capacity of conductor type k } \\ R P L_{L F}^{\text {Base }} & \text { Base case real power loss at LF } \\ K_{e} & \text { Cost of energy loss in Rs./kWh } \\ R P L_{L F}^{R C} & \text { Power loss with reconductoring at LF } \\ K_{p} & \text { Cost for peak losses in Rs./kW } \\ R P L_{P e a k}^{\text {Base }} & \text { Base case peak power loss } \\ L_{i} & \text { Length of branch } i \text { in km } \\ R P L_{\text {Peak }}^{R C} & \text { Peak power loss with reconductoring } \\ L(\lambda) & \text { Levy distribution function } \\ R_{i} & \text { Resistance of the ith branch } \\ M(\omega) & \text { Mantegna algorithm function } \\ N_{i}^{\text {Car }} & \text { Number of cars at } i \text { th node } \\ P L_{i}^{E V} & \text { EV load active power at ith node } \\ N_{i}^{S c o o t e r} & \text { Number of scooters at } i \text { th node } \\ P L_{i}^{\text {Base }} & \text { Base case Active power load at } i \text { th node } \\ N N & \text { Number of Nodes } \\ Q L_{i}^{\text {Base }} & \text { Base case reactive power load at } i \text { th node } \\ V_{\text {max }} & \text { Maximum voltage limit } \\ P L_{i}^{\text {Total }} & \text { Total active power load including EV load } \\ V_{\text {min }} & \text { Minimum voltage limit } \\ Q L_{i}^{\text {Total }} & \text { Total reactive power load including EV load } \\ \gamma_{M} & \text { Step size controlling factorr } \\ R P L_{P e a k} & \text { Real Power Loss at Peak Load } \\ \gamma & \text { Annual interest and depreciation factor } \\ & \end{array}$

\section{References}

1. Wang, Z.; Liu, H.; Yu, D.C.; Wang, X.; Song, H. A practical approach to the conductor size selection in planning radial distribution systems. IEEE Trans. Power Deliv. 2000, 15, 350-354. [CrossRef]

2. Mandal, S.; Pahwa, A. Optimal selection of conductors for distribution feeders. IEEE Trans. Power Syst. 2002, 17, 192-197. [CrossRef]

3. Ranjan, R.; Chaturvedi, A.; Solanki, S. Optimal Conductor Selection Of Radial Distribution Feeders Using Evolutionary Programming. TENCON 2003. Conf. Converg. Technol. Asia-Pac. Reg. 2003, 1, 456-459. [CrossRef]

4. Satyanarayana, S.; Ramana, T.; Rao, G.K.; Sivanagaraju, S. Improving the Maximum Loading by Optimal Conductor Selection of Radial Distribution Systems. Electr. Power Components Syst. 2006, 34, 747-757 . [CrossRef]

5. Kaur, D.; Sharma, J. Optimal conductor sizing in radial distribution systems planning. J. Electr. Power Energy Syst. 2008, 30, 261-271. [CrossRef]

6. Rao, R.S.; Satish, K.; Narasimham, S.V. Optimal conductor size selection in distribution systems using the harmony search algorithm with a differential operator. Electr. Power Components Syst. 2011, 40, 41-56. [CrossRef]

7. Franco, J.F.; Rider, M.J.; Lavorato, M.; Romero, R. Optimal conductor size selection and reconductoring in radial distribution systems using a mixed-integer LP approach. IEEE Trans. Power Syst. 2013, 28, 10-20. [CrossRef]

8. Abul'Wafa, A.R. Multi-conductor feeder design for radial distribution networks. Electr. Power Syst. Res. 2016, 140, 184-192. [CrossRef]

9. Samal, P.; Mohanty, S.; Ganguly, S. Simultaneous capacitor allocation and conductor sizing in unbalanced radial distribution systems using differential evolution algorithm. In Proceedings of the 2016 National Power Systems Conference (NPSC), Bhubaneswar, India, 19-21 December 2016; pp. 1-6. [CrossRef]

10. Abdelaziz, A.Y.; Fathy, A. A novel approach based on crow search algorithm for optimal selection of conductor size in radial distribution networks. Eng. Sci. Technol. Int. J. 2017, 20, 391-402. [CrossRef]

11. Ismael, S.M.; Abdel Aleem, S.H.E.; Abdelaziz, A.Y.; Zobaa, A.F. Practical Considerations for Optimal Conductor Reinforcement and Hosting Capacity Enhancement in Radial Distribution Systems. IEEE Access 2018, 6, 27268-27277. [CrossRef] 
12. Gampa, S.R.; Makkena, S.; Goli, P.; Das, D. FPA Pareto optimality-based multiobjective approach for capacitor placement and reconductoring of urban distribution systems with solar DG units. Int. J. Ambient Energy 2020. [CrossRef]

13. Burgio, A.; Cimmino, D.; Jasiński, M.; Leonowicz, Z.; Siano, P. A Heuristic Method to Calculate the Capacity of Residential PV-BESS in Providing Upward Flexibility Services in Energy Communities. IEEE Access 2022, 10, 2908-2928. [CrossRef]

14. Garcia-Valle, R.; Vlachogiannis, J.G. Electric vehicle demand model for load flow studies. Electr. Power Compon. Syst. 2009, 37, 577-582. [CrossRef]

15. Shireen, W.; Patel, S. Plug-in Hybrid Electric vehicles in the smart grid environment. In Proceedings of the IEEE PES T D 2010, New Orleans, LA, USA, 19-22 April 2010; pp. 1-4. [CrossRef]

16. van den Berg, M.; Lampropoulos, I.; AlSkaif, T. Impact of electric vehicles charging demand on distribution transformers in an office area and determination of flexibility potential. Sustain. Energy Grids Netw. 2021, 26, 100452. [CrossRef]

17. Brinkel, N.; AlSkaif, T.; van Sark, W. Grid congestion mitigation in the era of shared electric vehicles. J. Energy Storage 2022, 48, 103806. [CrossRef]

18. Iria, J.; Heleno, M.; Cardoso, G. Optimal sizing and placement of energy storage systems and on-load tap changer transformers in distribution networks. Appl. Energy 2019, 250, 1147-1157. [CrossRef]

19. Nick, M.; Cherkaoui, R.; Paolone, M. Optimal Allocation of Dispersed Energy Storage Systems in Active Distribution Networks for Energy Balance and Grid Support. IEEE Trans. Power Syst. 2014, 29, 2300-2310. [CrossRef]

20. Nick, M.; Cherkaoui, R.; Paolone, M. Optimal Planning of Distributed Energy Storage Systems in Active Distribution Networks Embedding Grid Reconfiguration. IEEE Trans. Power Syst. 2018, 33, 1577-1590. [CrossRef]

21. Marra, F.; Yang, G.Y.; Træholt, C.; Larsen, E.; Rasmussen, C.N.; You, S. Demand profile study of battery electric vehicle under different charging options. In Proceedings of the 2012 IEEE Power and Energy Society General Meeting, San Diego, CA, USA, 22-26 July 2012; pp. 1-7. [CrossRef]

22. Guo, C.; Zhu, K.; Chen, C.; Xiao, X. Characteristics and effect laws of the large-scale electric Vehicle's charging load. eTransportation 2020, 3, 100049. [CrossRef]

23. Zhang, J.; Yan, J.; Liu, Y.; Zhang, H.; Lv, G. Daily electric vehicle charging load profiles considering demographics of vehicle users. Appl. Energy 2020, 274, 115063. [CrossRef]

24. Hecht, C.; Das, S.; Bussar, C.; Sauer, D.U. Representative, empirical, real-world charging station usage characteristics and data in Germany. eTransportation 2020, 6, 100079. [CrossRef]

25. Sachan, S.; Kishor, N. Optimal location and optimum charging of electric vehicle based on sensitivity indices. In Proceedings of the 2015 IEEE Innovative Smart Grid Technologies-Asia (ISGT ASIA), Bangkok, Thailand, 3-6 November 2015; pp. 1-6. [CrossRef]

26. Gampa, S.R.; Jasthi, K.; Goli, P.; Das, D.; Bansal, R.C. Grasshopper optimization algorithm based two stage fuzzy multiobjective approach for optimum sizing and placement of distributed generations, shunt capacitors and electric vehicle charging stations. J. Energy Storage 2020, 27, 101117. [CrossRef]

27. Luo, L.; Wu, Z.; Gu, W.; Huang, H.; Gao, S.; Han, J. Coordinated allocation of distributed generation resources and electric vehicle charging stations in distribution systems with vehicle-to-grid interaction. Energy 2020, 192, 116631. [CrossRef]

28. Li, D.; Zouma, A.; Liao, J.T.; Yang, H.T. An energy management strategy with renewable energy and energy storage system for a large electric vehicle charging station. eTransportation 2020, 6, 100076. [CrossRef]

29. Bayram, I.S.; Galloway, S.; Burt, G. A probabilistic capacity planning methodology for plug-in electric vehicle charging lots with on-site energy storage systems. J. Energy Storage 2020, 32, 101730. [CrossRef]

30. Fan, V.H.; Dong, Z.; Meng, K. Integrated distribution expansion planning considering stochastic renewable energy resources and electric vehicles. Appl. Energy 2020, 278, 115720. [CrossRef]

31. Mehrjerdi, H.; Hemmati, R. Stochastic model for electric vehicle charging station integrated with wind energy. Sustain. Energy Technol. Assessments 2020, 37, 100577. [CrossRef]

32. Rahmani-Andebili, M.; Shen, H.; Fotuhi-Firuzabad, M. Planning and Operation of Parking Lots Considering System, Traffic, and Drivers Behavioral Model. IEEE Trans. Syst. Man, Cybern. Syst. 2019, 49, 1879-1892. [CrossRef]

33. Parastvand, H.; Moghaddam, V.; Bass, O.; Masoum, M.A.S.; Chapman, A.; Lachowicz, S. A Graph Automorphic Approach for Placement and Sizing of Charging Stations in EV Network Considering Traffic. IEEE Trans. Smart Grid 2020, 11, 4190-4200. [CrossRef]

34. Suresh, V.; Bazmohammadi, N.; Janik, P.; Guerrero, J.M.; Kaczorowska, D.; Rezmer, J.; Jasinski, M.; Leonowicz, Z. Optimal location of an electrical vehicle charging station in a local microgrid using an embedded hybrid optimizer. Int. J. Electr. Power Energy Syst. 2021, 131, 106979. [CrossRef]

35. Richardson, P.; Flynn, D.; Keane, A. Local Versus Centralized Charging Strategies for Electric Vehicles in Low Voltage Distribution Systems. IEEE Trans. Smart Grid 2012, 3, 1020-1028. [CrossRef]

36. Fachrizal, R.; Munkhammar, J. Improved Photovoltaic Self-Consumption in Residential Buildings with Distributed and Centralized Smart Charging of Electric Vehicles. Energies 2020, 13, 1153. [CrossRef]

37. Coffman, M.; Bernstein, P.; Wee, S. Integrating electric vehicles and residential solar PV. Transp. Policy 2017, 53, 30-38. [CrossRef]

38. Khalkhali, H.; Hosseinian, S.H. Multi-class EV charging and performance-based regulation service in a residential smart parking lot. Sustain. Energy Grids Networks 2020, 22, 100354. [CrossRef] 
39. Ayyadi, S.; Bilil, H.; Maaroufi, M. Optimal charging of Electric Vehicles in residential area. Sustain. Energy Grids Netw. 2019, 19, 100240. [CrossRef]

40. Gong, H.; Ionel, D.M. Optimization of Aggregated EV Power in Residential Communities with Smart Homes. In Proceedings of the 2020 IEEE Transportation Electrification Conference Expo (ITEC), Chicago, IL, USA, 23-26 June 2020; pp. 779-782. [CrossRef]

41. Ahmadi, S.; Arabani, H.P.; Haghighi, D.A.; Guerrero, J.M.; Ashgevari, Y.; Akbarimajd, A. Optimal use of vehicle-to-grid technology to modify the load profile of the distribution system. J. Energy Storage 2020, 31, 101627. [CrossRef]

42. Limmer, S.; Rodemann, T. Peak load reduction through dynamic pricing for electric vehicle charging. Int. J. Electr. Power Energy Syst. 2019, 113, 117-128. [CrossRef]

43. Haes Alhelou, H.; Mirjalili, S.J.; Zamani, R.; Siano, P. Assessing the optimal generation technology mix determination considering demand response and EVs. Int. J. Electr. Power Energy Syst. 2020, 119, 105871. [CrossRef]

44. Wang, H.; Sheng, L.; Yasin, G.; Wang, L.; Xu, H.; He, X. Reviewing the current status and development of polymer electrolytes for solid-state lithium batteries. Energy Storage Mater. 2020, 33, 188-215. [CrossRef]

45. Yasin, G.; Arif, M.; Mehtab, T.; Lu, X.; Yu, D.; Muhammad, N.; Nazir, M.T.; Song, H. Understanding and suppression strategies toward stable Li metal anode for safe lithium batteries. Energy Storage Mater. 2020, 25, 644-678. [CrossRef]

46. Mehtab, T.; Yasin, G.; Arif, M.; Shakeel, M.; Korai, R.M.; Nadeem, M.; Muhammad, N.; Lu, X. Metal-organic frameworks for energy storage devices: Batteries and supercapacitors. J. Energy Storage 2019, 21, 632-646. [CrossRef]

47. Hou, Q.; Yu, Y.; Du, E.; He, H.; Zhang, N.; Kang, C.; Liu, G.; Zhu, H. Embedding scrapping criterion and degradation model in optimal operation of peak-shaving lithium-ion battery energy storage. Appl. Energy 2020, 278, 115601. [CrossRef]

48. Dixon, J.; Bell, K. Electric vehicles: Battery capacity, charger power, access to charging and the impacts on distribution networks. eTransportation 2020, 4, 100059. [CrossRef]

49. Das, H.; Rahman, M.; Li, S.; Tan, C. Electric vehicles standards, charging infrastructure, and impact on grid integration: A technological review. Renew. Sustain. Energy Rev. 2020, 120, 109618. [CrossRef]

50. Anees, A.S. Grid integration of renewable energy sources: Challenges, issues and possible solutions. In Proceedings of the 2012 IEEE 5th India International Conference on Power Electronics (IICPE), Delhi, India, 6-8 December 2012; pp. 1-6. [CrossRef]

51. Al-Shetwi, A.Q.; Hannan, M.; Jern, K.P.; Mansur, M.; Mahlia, T. Grid-connected renewable energy sources: Review of the recent integration requirements and control methods. J. Clean. Prod. 2020, 253, 119831. [CrossRef]

52. Iria, J.; Scott, P.; Attarha, A. Network-constrained bidding optimization strategy for aggregators of prosumers. Energy 2020, 207, 118266. [CrossRef]

53. Yang, X.S.; Karamanoglu, M.; He, X. Flower pollination algorithm: A novel approach for multiobjective optimization. Eng. Optim. 2014, 46, 1222-1237. [CrossRef]

54. Alyasseri, Z.A.A.; Khader, A.T.; Al-Betar, M.A.; Awadallah, M.A.; Yang, X.S. Variants of the flower pollination algorithm: A review. Stud. Comput. Intell. 2018, 744,91-118._5. [CrossRef]

55. Jaipuria. Conductor Types and Specifications. Available online: http://www.jaipuriabrotherselect.com/acsr-conductorsaccessories.html (accessed on 8 December 2021).

56. Lakshmi, S.; Ganguly, S. Centralized and Distributed Battery Energy Storage System for Peak Load Demand Support of Radial Distribution Networks. In Proceedings of the 2019 IEEE Milan PowerTech, Milan, Italy, 23-27 June 2019; pp. 1-6. [CrossRef] 